\title{
Caged Morality: Moral Worlds, Subculture, and Stratification Among Middle-Class Cage-Fighters
}

\author{
Corey M. Abramson • Darren Modzelewski
}

Published online: 24 October 2010

C The Author(s) 2010. This article is published with open access at Springerlink.com

\begin{abstract}
Social scientists have long been concerned with how and why marginalized groups create and participate in subcultures. There has been significantly less work examining how those with access to conventional status and success participate in subcultures, often despite significant economic and social costs. The result has been lopsided theorizing that neglects much of the positive, affective, and moral appeal of subcultures at all levels of stratification. The participation of middle-class men and women in the rapidly growing world of cage-fighting speaks to this longstanding issue in the existing literature. We find these individuals participate in a sporting subculture that involves bodily, interpersonal, and professional sacrifices because they feel it gives them the ability to viscerally realize the widely shared American ideals that form the core components of their "moral world." The subculture holds particular sway over its members because they feel that its ideals, status hierarchies, and daily practices more directly embody the deeply embedded principles of middle-class morality and habitus than other elements of their lives.
\end{abstract}

Keywords Subculture $\cdot$ Sports $\cdot$ Cage-fighting $\cdot$ Morality $\cdot$ Embodiment $\cdot$ Mixed martial arts - Culture

This article was accepted by the former editor-in-chief Javier Auyero. The current editor, David Smilde, has approved of its publication.

C. M. Abramson $(\bowtie)$

Department of Sociology, University of California Berkeley, The Center for Urban Ethnography,

2420 Bowditch St., Berkeley, CA 94720-5670, USA

e-mail: coreya@berkeley.edu

D. Modzelewski

Department of Anthropology, University of California Berkeley, The Center for Urban Ethnography, 2420 Bowditch St., Berkeley, CA 94720-5670, USA

e-mail: darren@berkeley.edu 


\section{Introduction}

The case of cage-fighting, or mixed-martial-arts (MMA), presents a useful setting from which social scientists can improve our understanding of how and why even those with access to conventional avenues of success participate in subcultures. Unlike the inner-city African-American boxers studied by Wacquant (2004) or the street-corner men of Tally's Corner (Liebow 1967), many American mixed-martial-artists are college-educated, middle-class professionals who have substantial access to conventional avenues of material and social success. Far from providing tangible instrumental benefits in conventional systems of status, being a cage-fighter involves concrete social, bodily, and economic sacrifices, for members of the middle-class. ${ }^{1}$

The participation of these middle-class individuals in the world of cage-fighting speaks to a long-standing problem found in social-scientific understandings of subculture. Specifically, it highlights the inability of many conventional theories to adequately explain why both the marginalized and those with access to conventional avenues of status and success create and participate in subcultures. Sociologists, particularly ethnographers, have long examined the way those without access to conventional status systems create subcultural enclaves in which they feel known, valued, and respected (e.g. Becker 1963; Cressey 1932; Liebow 1967; Macleod 1987; Wacquant 2004; Willis 1976). The resulting theories, however, often have difficulty explaining why those with ready access to conventional forms of success still choose to create and participate in subcultures that entail concrete sacrifices rather than tangible benefits in the world outside. Consequently, work focusing only on marginalized populations foregrounds the exclusionary moment that drives people to these groups and obscures much about the affective and moral appeal that pulls them in at all levels of systems of stratification (Bennett 1999; Chaney 1994; Wacquant 2004).

While many theorists engaged in the "post-subculture debate" take steps to rectify some of these issues, definitive statements regarding the draw and function of subcultures remain elusive (Young and Atkinson 2008; Wheaton 2007). Our goal in this article is to offer empirical evidence about the structure and appeal of the cage-fighting subculture that will, in turn, provide a contribution to the debate regarding the utility of subculture as a concept for the social sciences, and the limitations found in the existing theories that formalize it. To this end, our research focuses on answering a concrete puzzle: Why do middle-class participants, with ready access to conventional avenues of success and status, participate

\footnotetext{
${ }^{1}$ Cage fighting, full contact fighting, ultimate-fighting, and mixed-martial-arts are all labels attached to this activity. They are often used interchangeably. Many athletes find the cage-fighting label distasteful, particularly those who are professional fighters or coaches whose livelihoods depend on it. They feel it plays upon imagined violence in the minds of observers while downplaying the skill and dedication they believe are at the sport's core. They argue that it does not accurately describe the sport or its venue. We acknowledge our subjects viewpoints, yet maintain the terms "cage-fighting" and "cage-fighter" throughout this article for three reasons. First, we want to acknowledge the historical presentation of this activity as a spectacle. This continues to play a large role in how its participants' actions are interpreted. Second, to many casual observers, this is the term by which this activity is known and discussed. Consequently, many mixed-martialarts organizations (including several large ones) market their events as "cage-fighting." Presumably this is a strategic move to reach the widest possible audience. Finally, one of the contentions of this paper is that within the middle-class milieu, there is a lingering negative stereotype of this activity, attached to the stark image of combatants ensconced in a cage. Without overly sensationalizing mixed-martial-arts, or imputing any moral implications to participation, we want to highlight that this activity has, and continues to be, seen as something spectacular by those both outside and within the subculture. We follow a long tradition of social-researchers in showing how even the seemingly most "extreme" or "exotic" cultural events, can be indicative of wide-spread and generalized social processes (Geertz 2000a [1972]).
} 
in the world of cage-fighting despite the number of bodily, interpersonal, and professional sacrifices this entails?

\section{Perspectives on Subculture}

Social scientific understandings of subculture can be broken up into roughly three theoretical traditions with distinct emphases: (1) The Chicago School tradition, with its emphasis on subcultures of urban deviance; (2) The Birmingham Centre for Contemporary Cultural Studies (CCCS) with its focus on class, conflict, style, and resistance; and (3) The "Post-subcultural" responses that question whether the notion of subculture should be reformulated or abandoned all together. While a general theory of subculture is beyond the scope of this article, we will highlight the main points of each tradition so as to situate our findings within the broader theoretical debates.

The early ethnographers of the Chicago School (e.g. Anderson 1923; Cressey 1932; Park 1925; Thrasher 1927; Zorbaugh 1929) examined the social worlds of marginal, deviant, and criminal groups that would later come to be known as subcultures. Research in this tradition focused on how social and environmental pressures led to deviance and disorder. A few decades later, but in the same general spirit, Albert Cohen (1955) concluded that subcultures were a form of collective problem solving for those deviant and typically marginalized individuals who could not otherwise adjust socially. Cohen (1955) and others (e.g. Becker 1963; Cressey 1932) typically framed subcultures as self-contained alternatives to mainstream culture with unique social forms, patterns of life, and status systems that were at odds with those of society proper

Later iterations of subcultural work were dominated, or at least highly influenced, by the Birmingham Centre for Contemporary Cultural Studies (CCCS). The CCCS theories emphasized class conflict, ideology, conscious opposition, political resistance, and style. Birmingham researchers focused on describing the way groups (typically of white workingclass youth) fought to create an identity that would stand in contrast and critique of mainstream society (e.g. Clarke et al. 1976; Hebdige 1981; Willis 1976). Their primary concern was to understand the way subcultures' real or imagined solutions related to larger issues of class inequality and social reproduction (Cohen 1972; Clarke et al. 1976). Still, like the theorists of the Chicago School, their research emphasized how socially marginalized groups responded to the dilemmas created by their social position.

The Chicago School's take on subculture was widely criticized for its narrow focus, immutability, and uncritical construction of deviance (Becker 1963; Cloward and Ohlin 1960; Sykes and Matza 1957). Likewise, the CCCS vein of subcultural theorizing has been roundly criticized for its selective focus on class as opposed to other elements of stratification such as gender or race (Bennett 1999; Chaney 1994) and the overemphasis on politics, semiotics, and resistance (Frith 1983; Kahn-Harris 2004; Miles 1998; Muggleton and Weinzierl 2004). ${ }^{2}$

In light of the critiques of both Chicago School and CCCS subcultural theory, many recent scholars have questioned whether the concept of subculture has any empirical utility, or if it should be replaced by less conceptually restrictive terms such as neo-tribe, scene, lifestyle group, or taste-culture (Bennett 1999; Martin 2004; Muggleton 2000; Redhead 1993; Thornton 1996). "Post-subcultural" theorists continually point out how previous

\footnotetext{
${ }^{2}$ For a fuller treatment of the conceptions and history of subcultural theory, as well as their critiques, see Hughson (2008), Thornton (1997), Wheaton (2007), Young and Atkinson (2008).
} 
understandings of subculture disproportionately discount the affective (Sweetman 2001) and moral (Atkinson 2008; Wacquant 2004) appeal of subcultural participation. Despite the problematic ways that subculture has been theorized, we agree with those who argue that the concept is analytically durable and empirically powerful (i.e. Hughson 2008; Wheaton 2007; Widdicombe and Wooffitt 1995; Young and Atkinson 2008). ${ }^{3}$

\section{Key Characteristics of Subculture: A Working Definition}

Before moving on to the case at hand, it is necessary to detail the key components to a working definition of subculture. We begin with the understanding of subcultures as social subsystems bounded by shared cultural elements such as communal meanings, motivations, and strategies (Fischer 1975; see also Gordon 1947; Sánchez-Jankowski 2008). These "small social structure[s] within the larger dominant culture, [are] composed of individuals sharing similar values, behaviors, attitudes, symbols, and rituals, which set them apart from the larger culture, dominating their style of life and stabilizing over time" (Young and Atkinson 2008, p. 9; See also Donnelly 1981). Along these lines our working definition of subculture has three key characteristics.

(1) Subcultures are fundamentally bounded status systems, separate though not autonomous from the status systems of society proper, which are based upon a shared and recognized moral world.

Following classical sociological understandings, we define a moral world as a set of assumptions about the world, shared by a group and held by individuals, that describes what is good and bad, right and wrong, sacred and profane, worth pursuing and worthless (Durkheim 1995 [1912]). ${ }^{4}$ Subcultures provide for the social distribution of honor (Weber 1946), understood as the status or esteem any given individual holds in the eyes of other members of the subculture. Subcultural boundaries, and the status hierarchies they circumscribe, are ostensibly based upon perceived realization of the ideals that constitute the moral world.

(2) A subculture's status system, cultural underpinnings, and boundaries must be recognized by those in the subculture.

Members are finely attuned to where subcultures begin and end; who has status within the group and who is a pretender (Becker 1963; Thornton 1996). There is an embedded sense of "us" and "them," "musician" and "square" (Becker 1963), "hip" or "mainstream" (Thornton 1996), "hero" and "coward." These social divisions are fluid and permeable (Donnelly 1993), and they can shift over time (Clarke et al. 1976; Fine

\footnotetext{
${ }^{3}$ There is a rich literature examining sport subcultures in particular, which may be a fruitful venue for revisiting the concept, as these groups tend to include various age groups who coalesce around activity rather than consumption (Hughson 2008; for a review see Wheaton 2007; Young and Atkinson 2008).

${ }^{4}$ We posit, with many before us, that shared inter-subjective meanings are the foundation of human culture. These meanings undergird, enable, and ultimately constrains all social life (Bourdieu 1984; Durkheim 1984; Geertz 2000b [1966]; Searle 1995; Sewell 1992; Swidler 2000; Taylor 1985). Moral worlds are subsets of this larger pool of meanings. Moral worlds need not be a neatly coherent worldview. They can, and do, overlap. Further, moral worlds do not include all of the meanings, motivations, or strategies of action, available to a group of individuals. Rather, they are a very specific subset of shared understandings that indicates socially validated motivations (Mills 1940; Vaisey 2009) and strategies of action (Swidler 1986, 2000). While this moral world can point people towards particular ends (Geertz 2000b [1996]; Laitin 1986), it does not need to be internalized to do so (Swidler 1986, 2000). Their codification by institutions, and the corresponding sanctions for deviance, are enough to direct action (Swidler 2000; Derné 1994).
} 
and Kleinman 1979; Muggleton 2000). Still, the distinctions are real and meaningful for the "insiders," who espouse a level of difference (and often superiority) to those "outside" the group (Atkinson 2008; Becker 1963; Thornton 1996).

(3) Membership in a subculture is said to be comparatively volitional, when participation cannot be reduced to birth or material necessity.

While all social relations include varying levels of both constraint and choice, there is a key analytical difference between membership in a social subsystem that one belongs to by birth or social location a priori, and the ones that people choose to participate in given the sets of structural constraints that delimit their lines of possible action (Fine and Kleinman 1979). The point here is simply to recognize that there is a critical distinction between the bounded groups people can choose to join (e.g. cagefighters), and those to which we are born and socialized into such as an ethnic enclave (Fischer 1975) or a "sub-culture of scarcity" (Sánchez-Jankowski 2008). Of course, even the ability to belong to relatively volitional subcultures such as punks (Hebdige 1981), boxers (Wacquant 2004), or jazz musicians (Becker 1963), is conditioned by social characteristics such as class, race, gender, and sexuality. Still, membership is never simply a given by birth. It requires an initial agentic moment of association, and subsequent active identity management by members. These comparatively volitional subcultures are the focus of this article. ${ }^{5}$

The working definition of subculture outlined above opens the door to understanding the general elements of subcultures that appeal to those at all levels of systems of stratification, as well as the specific elements that are unique to particular social strata. It therefore provides a useful starting point for understanding why the middle-class cage-fighters in this study are willing to make concrete sacrifices to participate in a social world that is often seen as marginal by those outside.

\section{Methods of Inquiry}

To investigate why even those with ready access to conventional pastimes and success participate in subcultures, we engaged in 2 years of ethnographic research in five cagefighting, or mixed-martial-arts (MMA), gyms on the east and west coasts of the United States. Following the movement towards examining the embodied experience of sporting subcultures, we immersed ourselves in the physical, cultural, and sensorial lifeworld of our subjects by actually "getting into the ring" (Butryn and deGaris 2008, p. 337; Wacquant 2004). During our study, we became amateur cage-fighters, secured positions as insiders in the MMA community, and gained access to the ways fighters think about, talk about, feel, and live this activity (Photograph 1). We paid particular attention to the habitus of these individuals, that is to say, their "acquired, socially constituted dispositions" (Bourdieu 1990a, pp. 12-13; Wacquant 2009). These are patterned ways of thinking and experiencing the world that are inculcated and reproduced through daily practices and interactions (Bourdieu 1984, 1990b).

As participant observers, we trained in a given gym at least once a day (5-6 days per week), and twice a day when we were preparing for competitions. We typically spent

\footnotetext{
${ }^{5}$ Further, the forms of these comparatively volitional subcultures are typically less instrumental (at least in a material sense) than environmental subcultures or other forms of community and sociability.
} 


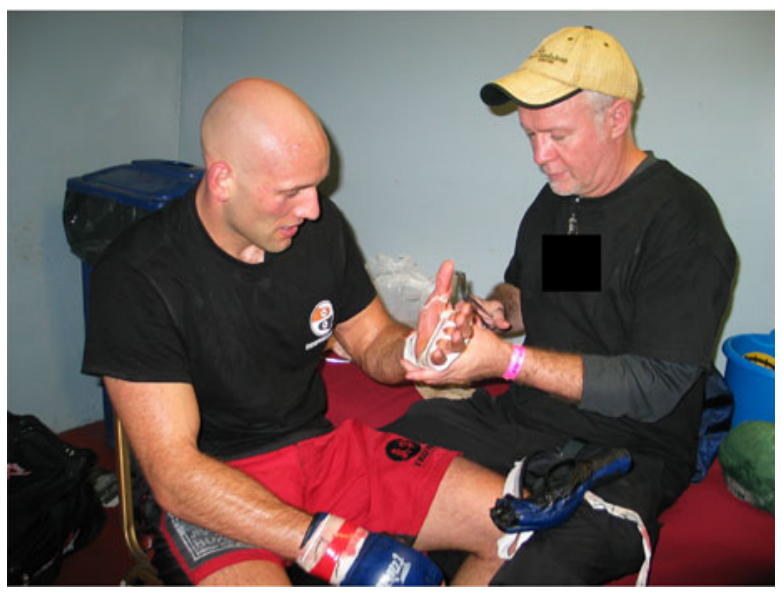

Photograph 1 Co-author, Darren Modzelewski gets cleaned up by a corner man after his successful amateur cage-fighting debut. Photograph by Corey M. Abramson

between 20 and 30 hours per week in the field. We experienced the various injuries that often plague combat athletes, such as broken noses, fingers, and toes; injured joints; cracked ribs; strained ligaments; and general fatigue. By subjecting ourselves to the daily trials of training we were able to become part of the fight world. We spent time with our subjects before and after training in settings ranging from the gym to the bar; listened to them talk about jobs and spouses; went out with them on the weekends; spent time in their homes; and generally did the same things any other member of the subculture would do. In reconstructing their understandings, we followed a strategy analogous to that employed by Wacquant (1995b) in his study of boxers. We took "seriously what [fighters] have to say about their occupation: how they think and feel about this harsh trade to which they are willing to give so much, what virtues it holds for them, and how it affects their life and self" (Wacquant 1995b, p. 490). ${ }^{6}$

In addition to spending time with fighters in and out of the gym, we competed regularly in local and regional events frequented by cage-fighters. These events included everything from informal inter-gym fights, to local Muay Thai kickboxing events, to large national Brazilian Jiu-Jitsu championships. We also participated in mixed-martial-arts bouts. Near the end of the research, one of us fought in a cage in front of a full house of 1,500 spectators in a locally televised mixed-martial-arts bout. The other, who had a black belt in Judo prior to beginning the project, coached and performed "corner work" for a cohort of younger fighters as they participated in amateur, semi-pro, and professional events. To gain a broader picture of the subculture during our time in the field, we also attended many events, both large and small, as spectators. We attended local, national, and international mixed-martial-arts title fights in a total of five different cities.

\footnotetext{
${ }^{6}$ It is important to note that although we pay a great deal of attention to what the fighters in our study have to say about their craft, we see their speech behavior and interview responses as indicative of shared intersubjective cultural frameworks, which are key in understanding the social mechanisms at play in this subculture (Derné 1994; Swidler 2000). It is necessary to understand the collective representations upon which these frameworks are built and reproduced. As we will show, many of these normative and widely espoused justifications often function by obscuring underlying inequalities around issues of race, class, and gender.
} 
By participating in various roles as "fighter," "coach," and "fan," we obtained a broader perspective of the cage-fighting world. Occupying different roles at different times and places allowed us to immerse ourselves in various aspects of the subculture and to record a wider array of speech accounts and behavior than might otherwise have been possible (Butryn and deGaris 2008). In short, we had the opportunity to be both "participant observers" and "observing participants" (Woodward 2008).

In the interest of disclosure, reflexivity, and the evaluation of evidence, it is useful to note those aspects of our appearance that may have affected the data we collected. In any athletic subculture, factors such as race, class, gender, sexuality, and prior sport participation are potential axes of status that mediate participation in the social world and the responses of those who normally occupy it (Burawoy 1998; Wheaton 2004; Woodward 2008). In the case of cage-fighting, both authors appeared similar to the individuals in our study. Most outside observers would perceive us to be white, middle-class males and we both had previous experience in athletics. ${ }^{7}$ This allowed us to blend in with cage-fighters with relative ease.

Our ability to blend in with the research subjects was methodologically advantageous for four reasons. First, it allowed us to gain near total access to the research sites. We were able to accompany fighters, coaches, fans, and fight promoters during all stages of the fighting process: from daily training, to weighing in before contests, to attending rules meetings, to the fight itself, and the parties afterwards. Second, our ability to blend in minimized the "context" or "interaction" effects that might lead subjects to act differently in the presence of a researcher who is perceived as an outsider, and therefore different (Burawoy 1998). Although our subjects were all informed we were doing an academic project, our full participation in subcultural activities and demographic typicality ensured we were counted among members of the subculture. This improved our ability to observe general patterns. Third, through past experience with sporting subcultures and the middle-class world, we had a basic understanding of many of the behavioral and speech cues of our subjects. This knowledge, whether acquired before or during fieldwork, is essential for understanding what is observed in ethnographic research (Sanchez-Jankowski 2002). Fourth, we had enough status in the subculture (bolstered by previous athletic and martial arts experience) to make successful authenticity claims (Wheaton 2004), while observing the general ebb and flow of social life. This allowed us significant access to the general patterns of meaning and behavior that are the focus of our analysis (Sanchez-Jankowski 2002). ${ }^{8}$

In addition to our observations and informal conversations, we conducted 25 semistructured in-depth interviews of competitive middle-class fighters. These interviews augmented our ability to examine the underlying cultural frames and moral understandings of the subculture. We interviewed big-time contenders, up and coming amateur fighters, and local "gym rats" who competed but never fought in front of a large crowd or made money from fighting. We employed a snowball sampling technique whereby we selected one

\footnotetext{
${ }^{7}$ With previous athletic experience, one is assumed to be hard-working, dedicated, and focused. These are key attributes of the moral world of cage-fighting and thus a potential avenue to increased legitimacy and status. For example, the Judo black belt held by one of the authors is a marker of prestige similar to varsity wrestling experience. While not as extreme as a black belt in Brazilian Jiu-Jitsu, it is enough to show that the athlete is serious about training and deserving of respect.

${ }^{8}$ This is not to say our strategy or social position was without costs. When a researcher is viewed as an insider or participant, it is both important and more difficult to probe and question the taken-for-granted commonsense assumptions that subjects may be more likely to articulate in the presence of an outsider. This approach also denied us access to the rich data that can be generated using interactionist procedures and breaching experiments. Still, we believe overall the positions we assumed, and the strategies we pursued, were the best available given our individual biographies and the questions that guided our inquiry.
} 
fighter from each gym, then asked them to refer others. The idea was to expand out from the gym to tap fighters' networks (see Atkinson 2008 for a similar strategy). Our interviewees included members of the five gyms where we conducted participant observation, as well as other fighters in their personal networks. All of our interviewees were employed in what would be considered professional middle-class occupations (e.g. real estate brokers, doctors, teachers, etc.). All but one had at least a bachelor's degree. All had previous athletic experience. Most were in their late twenties or early thirties. The respondents for our interviews ranged from 22 to 39 years of age. Five of our interviewees were women. Although many were White, we also interviewed and observed Latino, African-American, and Asian-American fighters. To organize all the data, we entered our field notes and interview transcripts into a computer assisted qualitative data analysis program, which facilitated the coding, analysis, and presentation of the findings. ${ }^{9}$

\section{Results}

In this section we do four things: first, we provide a brief description of cage-fighting in the United States to orient the reader. Second, we describe some of the sacrifices made by middle-class people who participate in cage-fighting in terms of the body, relationships, and work. Third, we examine two popular explanations for why these participants are drawn to the world of fighting, and evaluate their plausibility in light of our data. Finally, we offer our explanation for why cage-fighting is so important to these individuals by charting their moral world and "collective dispositions" (Wacquant 1995b) and examining the boundaries and subculture they create.

\section{What is Cage-Fighting?}

During its brief existence, cage-fighting has been a perennial object of media attention and punditry. Even in its new rule-bound form, its violence has simultaneously been decried as "human cockfighting" (MSNBC 2007; Silverman 1998; Weinreb 2007) and lauded as the "real deal" or the "next stage in the evolution of martial arts" (Gentry 2001; Krauss and Bret 2002; Mayeda and Ching 2008; UFC 2009). While there has been a vein of research examining whether the emergence of this activity is part of a civilizing or de-civilizing process in Norbert Elias' sense (e.g. van Bottenburg and Heilbron 2006, 2009), there is relatively little academic work examining the social world of cage-fighting, or the underlying processes that this particular subculture can illuminate.

So what is this activity and what does it look like? The Ultimate Fighting Championship (UFC), arguably the most widely-recognized mixed-martial-arts organization in the world at present, offers a useful starting definition: "MMA is an intense and evolving combat sport in which competitors use a variety of forms of fighting that include Brazilian Jiu-Jitsu, Judo, Karate, boxing, kickboxing, wrestling and others to their strategic and tactical advantage in a supervised match" (UFC 2009). Mixed-martial-arts is different from other combat sports and martial arts in that no single skill set (e.g. boxing, wrestling, Brazilian Jiu-Jitsu) is isolated from the others. At the professional level participants can exchange punches, kicks, knees, and elbows in almost any position. While standing, fighters typically employ techniques learned from Western Boxing and Muay Thai Kickboxing. Fighters can

\footnotetext{
${ }^{9}$ We used ATLAS.ti for this purpose. See Abramson (2009, pp. 71-72); and Dohan and Sanchez-Jankowski (1998) for a discussion of the role of these programs in qualitative research.
} 
also wrestle one another to the mat using Judo, Greco-Roman, or Free Style wrestling techniques. During the fight, participants may apply a number of submission techniques such as chokes and joint locks derived from grappling disciplines such as Judo, Brazilian Jiu-Jitsu, or Sambo. Fights are sometimes bloody, and can end by knockout, submission, referee's stoppage, judges' decision, or the corner "throwing in the towel" (Photographs 2 and 3).

After being relegated to live events at Native American reservations and video distribution between 1997 and 2001, cage-fighting reemerged as a major combat sport in the new millennium. ${ }^{10}$ Strategic marketing (e.g. including not calling events cage-fights), the introduction of myriad new rules, the support of state athletic commissions, and a popular reality show called "The Ultimate Fighter," helped the growth of the new, more sportive form of this activity. Since we began this project in 2005, mixed-martial-arts has gone from a fringe activity of interest to only a handful of people, to a major type of sporting event that can be seen on prime time network television and is also covered by ESPN and Sports Illustrated. Its top athletes have attained a modicum of celebrity status. Given this rebirth, it is not surprising that mixed-martial-arts is often described as the fastest growing sport in the United States (Lubin 2008; MSNBC 2007; Sandomir 2007; Weinreb 2007).

Yet, cage-fighting is a combat sport, and a relatively new one in the minds of the American public. It still garners negative media attention. Despite an increasing presence in popular media, many still question the legitimacy of cage-fighting as a sport, wonder whether it has any social value whatsoever, and shake their heads when discussing what could possibly motivate its participants.

\section{Sacrifices and Tensions}

During our research, the middle-class fighters in our study made concrete sacrifices to participate in the world of cage-fighting. All of the fighters we interviewed, and many we observed, were employed in diverse professional occupations. For example, our subjects included a microbiologist, a medical doctor, a financier, a high school teacher, and a doctoral candidate at a major research university. These people had access to more conventional pastimes, social settings, and sources of prestige. Consequently, they were aware of the tensions, sacrifices, and predicaments associated with participating in a marginally accepted combat sport that is still seen by many as ultra-violent. They were conscious of the fact that participation in a subculture often creates tensions in the world outside (Becker 1963; Cohen 1955; Wacquant 1995a, b). Yet, their participation in the world of cage-fighting remained an "organizing fixture in their lives" that determined the way they approached myriad daily practices from food intake and sleep, to time with the family (Atkinson 2008, p. 296). The average participant in the gyms we studied spent upwards of 20-30 hours per week training, doing physical conditioning work, and sparring. In order to do this, the fighters in our studies faced tensions and made sacrifices in three areas of their lives: the body, inter-personal relationships, and in the world of work.

Still, fighters acknowledged participation in mixed-martial-arts as one of the most important aspects of their life. As John ${ }^{11}$ a 31-year-old holistic health practitioner noted, "I didn't know what I was getting myself into when I started-all I knew was that it was

\footnotetext{
${ }^{10}$ The history and trajectories of MMA in Brazil and Japan, the two other locations where the sport is most popular, are very different from that of the United States. For more information see Gentry (2001), Krauss and Bret (2002), and Sheridan (2007).

${ }^{11}$ The conclusions we draw in this paper are based upon observable patterns of speech and behavior. The quotations we have selected are representative of those patterns. We use pseudonyms to protect the identities of the fighters and gyms in our study.
} 


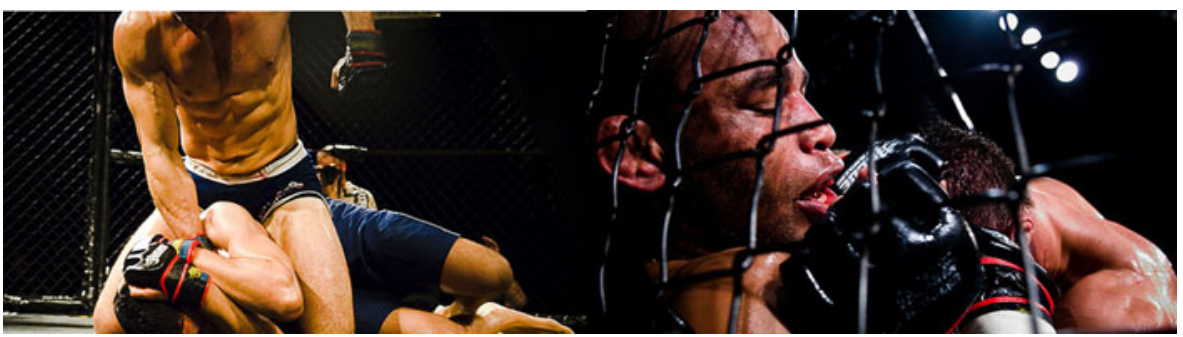

Photograph 2 Mixed-martial-arts matches in a cage. Photographs by Stefan Tell

something very important to me; it had an ethereal feel, that importance." We will show that the appeal of this subculture lies in the fact that participants feel its status hierarchy and practices better embody the deeply held and shared ideals of their middle-class morality and habitus than other aspects of their lives. We now look at the three areas in which the cagefighters in our study made sacrifices in turn.

\section{The Body}

The individuals we studied had to deal with the physical toll that living, training, and practicing as a cage-fighter takes on the body. Scholars who have done work on sports in general, and combat sports specifically, have often commented that participants must endure pain on a daily basis. Further, athletes typically see continued participation in their

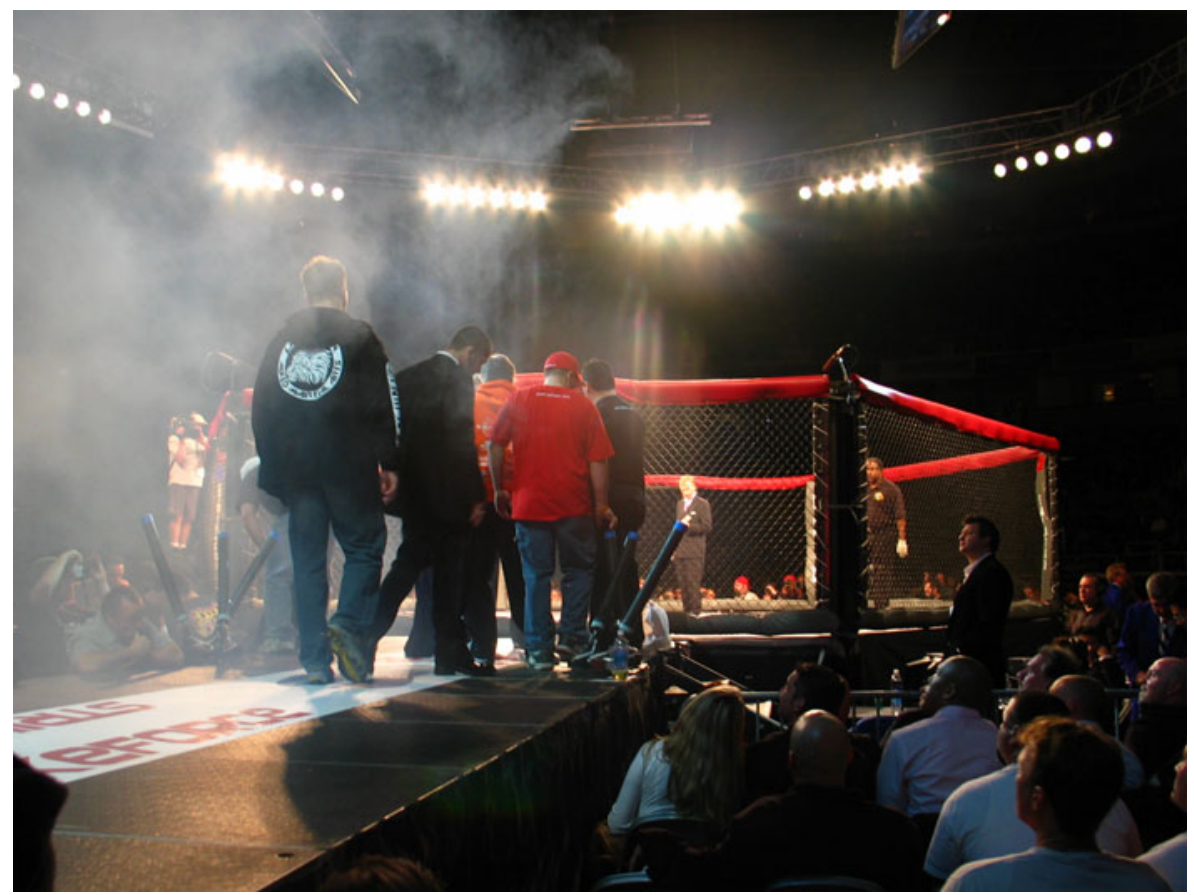

Photograph 3 Cage-side view of a large mixed-martial-arts event featuring over 16,000 spectators. Photograph by Corey M. Abramson 
sport or pastime as more important than allowing the body to heal (Dunning 1999; Pike 2005; Sabo 1986; Smith 2008a, b; Young et al. 1994). Being a fighter is essentially an exercise in managing chronic injuries (Wacquant 2004). As one coach in our study poignantly remarked to a fighter complaining about an injured shoulder, "there is no such thing as a healthy athlete." Many of the fighters we studied had constant back and joint problems associated with daily grappling and sparring. Several had sport related injuries that required surgery, and most were aware of the long-term health risks such as arthritis, back problems, and the potential for brain trauma. They knew about and were willing to accept these risks (see Smith 2008b for a similar finding among professional wrestlers).

When we asked fighters if the potential for injury deterred them from continued participation in the sport, none replied that it did. Instead, they employed a narrative of stoicism that recognized injury, both acute and cumulative, as "just part of the game." As in other sports, the ability to be tough and to endure pain and injury was understood as an axis of prestige (Atkinson 2008; Birrell 1981; Smith 2008b). Danny, a 27-year-old small business owner put it succinctly when he said to be a fighter, "you have to be tough." For fighters, like other athletes, the ability to ignore or manage pain is a marker of moral distinction (Atkinson 2008; Smith 2008b; Wacquant 1995a, 2004). Physically inscribed bio-cultural markers such as a muscular physique or "cauliflower ears" (see Photograph 4) serve as badges of honor and criteria for moral appraisal in the world of cage-fighting. In combat sports, as in other arenas of social life, the body and its presentation signify membership in the group. This point was underscored when we observed two acquaintances, who had not seen each other in some time, chat at a local event. As they told us later, the last time Jimmy and Doug had seen each other was 3 years prior to Jimmy beginning to train as a cage-fighter. Upon first seeing the now much more muscular Jimmy, Doug remarked, “damn, man! You even walk like a fighter!” Jimmy just smiled in response.

For fighters, the body is more than just a signifier. It is a multifaceted tool that comprises both the sword and shield of a sportive engagement (Wacquant 2004). While the ability to endure pain, suffering, and injury in the course of training and fighting are taken as a marker of status and morality (Atkinson 2008; Birrell 1981; Smith 2008b; Wacquant 2004), having a body that can function at the required level is a prerequisite for participation as a fighter. In many ways an injury can call into question the fighter's identity and status in the subculture, while denying him or her access to the affective (Sweetman 2001), corporeal (Wacquant 2004), and social pleasures that participation entails. Further, the fighter's

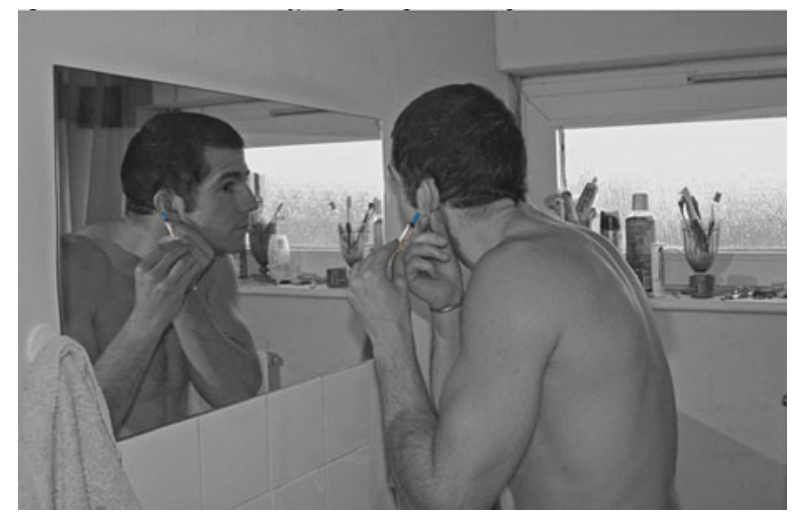

Photograph 4 Fighter draining cauliflower ear. Photograph by Huffy Houghoughi 
"bodily capital" (Wacquant 2004), physique and technical skill set (all predictors of social position in the subculture), are likely to atrophy during the time spent recovering from an injury.

When injuries do occur, fighters are often less concerned about the long-term implications for their bodies than with the time missed from training. In the discourse of fighters, the real sacrifice associated with injury is social rather than physical: it is in the time away from the gym. An event during our field research illustrated this vividly. Tim, a 33-year-old manager in the entertainment industry, broke down crying after injuring his neck while grappling. When one of us asked if he was okay, he replied emotionally, "I'm not crying from the pain. I could give a shit. I know what this means. I've felt this before. This is going to be 6 months off the mat. That's why I'm upset.", 2

\section{Relationships}

The fighters in our study also experienced strains on their familial and romantic relationships as a result of their participation in the cage-fighting subculture. For our middle-class respondents, the sheer time commitment involved in actively competing as a fighter affected their ability to maintain relationships at home and at work (see Atkinson 2008 for a similar finding among triathletes). Fighters reported that spouses and partners often grew jealous of the endless hours at the gym. The following quotes explain the strain that participation in cage-fighting places on relationships:

Danny, the 27-year-old small business owner: "Uh, it's hard to explain it to your girlfriend. She doesn't quite understand. You have to sacrifice a lot. I mean, my life right now is training and work. And any free time I'm spending with my family and friends but that's pretty minimal now."

Jim, a 22-year-old nurse: "The time away from that relationship [due to training] was a challenge."

Ed, a 22-year-old MBA student: "My girlfriend said to me, 'You spend so much time in the gym, I never get to see you, we have to eat late and you're too tired to have sex. I'm tired of it; it's me or the gym.' I was like, Okay, the gym."

While the example above with Ed is extreme, nearly all of the fighters in our study reported experiencing some strain on their relationships and family commitments outside of the gym.

\section{The World of Work}

We now turn to the tensions the middle-class cage fighters in our study faced in the world of work. Fighters often commented on the negative perceptions they faced in professional settings. The following quotations are indicative of these experiences:

Nick, a 32-year-old chemist: "When I started competing about a year and a half ago, people saw it as a back-yard, barn-yard chicken fight. When I did show up to work with black eyes, I was shunned..."

\footnotetext{
${ }^{12}$ Subsequently, the injury turned out only to be a sprain, and Tim was back within 2 weeks. When asked about it, he said calmly "Well, injury is part of the game, but I hope that shit doesn't happen again; I hate not being able to train."
} 
Jake, a 39-year-old working in real estate: "The people at work think I'm crazy when

I come in with a black eye or a bruise on my face or arms, but I don't really care. This is who I am."

The fighters we observed and interviewed were aware that they were subject to potential stigmatization outside the gym or cage. They are what Erving Goffman (1963) calls "discreditable" individuals. Their participation in the world of cage-fighting subjects them to the possibility of a status loss in other spheres of life even though their "differences [from others] is not immediately apparent and is not known beforehand" (Goffman 1963, p. 42). As a consequence, these people often engage in strategies for managing this information, to avoid having their activity known, to maintain the expectations of a social situation, and to prevent their moral status being cast into doubt. As Todd, a 30-year-old professional fighter who also worked full time at a biomedical lab, noted: "Everyone's gonna think a jock is dumb, and everyone's gonna think that a jock that punches other people and gets punched is extra dumb.... I just try to avoid it [the conversation]." Many felt that defending themselves against this onslaught was a tiresome hassle. Jake, the real estate worker, commented that he was exhausted because he had to "be extra nice so people won't get the wrong idea, so they'll get to know the real me." Most of the middle-class fighters in this study did not seek to flaunt that identity. Unlike those gym-mates who were teenagers or members of the working class, they did not walk around wearing clothing that associated them with cage-fighting (except at cage-fighting events). Rather, on average, many sought to hide their participation in order to minimize friction in interactions outside of the sportive sphere. ${ }^{13}$

While only a handful felt their participation prevented them from promotions, many felt that constantly defending themselves, or keeping up a façade, was a tiresome experience. Ken, a 31-year-old working as a medical administrator, noted, "At work I try to avoid the discussion...I try to keep those two worlds apart." Almost all felt that participating in MMA affected the time and energy they had available for their careers, and consequently limited how effective they could be at work. Some also felt that work was getting in the way of their potential of being a fighter. During the course of our study, several fighters even quit their full-time jobs and took up part-time work, willingly taking severe pay cuts in order to have more time to train and fight. While this response was extreme, the difficulty of managing work and lifestyle-sport commitments weighed heavily on those in our study (see also Atkinson 2008).

\section{Incomplete Explanations for the Appeal of Cage-Fighting}

There are two popular, but incomplete, explanations for why middle-class individuals participate in the cage-fighting subculture. The first posits that activities like cage-fighting are about males attempting to exert gender dominance by creating a subculture based $a$ priori around masculinity, often in the hopes of reclaiming a lost or missing warrior society (Gibson 1994; Hopton 2002; Kreager 2007; Malcom and Velija 2008; Messner 1990). The second explanation states that fighters are exceptionally violent individuals; modern day gladiators seeking an unabashedly violent domain to relax the frustrations associated with living in a modern world subject to increasing restraint (van Bottenburg and Heilbron 2006; see also Sammons 1988).

\footnotetext{
${ }^{13}$ There are some exceptions. One lawyer in our study said he frequently evoked his role as a fighter, because he felt it would impress or intimidate colleagues. It is also possible that the guardedness exhibited by the fighters in our study may change as the activity becomes more popular.
} 


\section{Sex, Gender, and Homo-Sociability}

We begin by examining the notion that the cage-fighting subculture is primarily about masculinity. Some scholars interested in the intersection of gender and sport argue that sports - and in particular contact sports such as Judo, boxing, football, or hockey formalize, organize, and provide substantive support for embodying masculine ideals and norms such as aggression, competitiveness, physical strength, and fitness (Messner 1989, 1990, 2002; Hopton 2002). "Masculine" ideals are often contrasted to "feminine" norms of passivity, cooperation, and care giving (Martin 1998; Thorne 1993). If this were the case in cagefighting, we would expect to encounter attitudes and posturing implicitly or explicitly supporting this hyper-masculine hypothesis. One of Messner's interviewees provides a perfect example of this type of attitude when he states, "A woman can do the same job as I can do - maybe even be my boss. But I'll be dammed if she can go out on the football field and take a hit from Ronnie Lott" (Messner 1989, p. 79). In the quote above, the world of sport becomes a place that lauds specifically masculine abilities.

In all the cage-fighting gyms we observed, however, the vast majority of male subjects encouraged, supported, and actively trained with women. Further, men typically engaged in cooperation, social support, bodily care giving, and other stereotypically "feminine" activities with their peers. As we will show, over-aggressiveness and the "win-at-all-costs" mentality were stigmatized, while caring was valued. The organizing principal of meritocracy overshadowed gender-based divisions in both activity and status within the gym. Of course, the notion of meritocracy is founded upon, benefits from, and reinforces specific inequalities, including those related to sex and gender. Still, among the cagefighters in our study - both male and female — gender was not explicitly deployed as an organizing principle that determined participation or the allocation of prestige.

We found that while there was occasionally talk of being a warrior, or men having a primal urge to fight, these topics invariably arose in settings involving outsiders, such as when journalists have asked fighters to attempt psychological self-analysis (i.e. MSNBC 2007). In our study fighters typically did this in the presence of outsiders. We find this to be a "party line" - a statement of a particular ideology that has little to do with how fighters actually make sense of their activity (see also Crigger 2008; Mayeda and Ching 2008; Sheridan 2007). For some fighters, talk of being a "warrior" was an inside joke, accompanied by air-quotes and laughter. Spending lots of time with a large number of fighters made it clear to us that they did not use these sorts of framing to collectively understand or describe this activity among themselves, but only to portray it publicly. It was not a large part of "the pugilistic point of view" that permeated and organized their world (Wacquant 1995b).

In their daily interactions, fighters did, however, continually emphasize the creation of a community of like-minded individuals, willing to undergo similar trials and rites - such as training, fighting, and dealing with injuries. Being male was not a prerequisite to membership. Women were not denied access, sanctioned, or admonished in the gym or the ring by other fighters or coaches because of their gender, provided that they participated in the same activities and accepted and lauded similar sportive virtues such as gameness, heart, courage, and aestheticism (Birrell 1981, pp. 365-372; Crigger 2008). According to our subjects, women were ostensibly assigned status based on the same criteria as men. When we asked Ken, the 31-year-old medical administrator, if women can attain the same position as men in the gym and be seen as part of the community, he noted in a manner typical of our respondents:

"It doesn't matter if you are a guy or a girl; if you stick around you get respect from your training partners. If they come consistently and put in their best effort, they get my respect." 
Bob, a 28-year-old former soldier, stated: "Unequivocally, yes. Yes, women can be a part of this world. For our gym, it usually takes someone who has a sarcastic sense of humor and who's tough as nails. If they're that way, male or female, you're going to be respected and we're going to celebrate you for that."

When we asked female fighters if they felt like they were treated equally, their responses were similar. When Shana, a 32-year-old medical student, was asked if she felt prejudice in the gym because she was a woman, she responded, "To be honest, I've found people to be generally respectful and quite receptive." Likewise, Michelle, a 29-year-old teacher, noted, "sometimes new guys feel sort of weird rolling [grappling] with a girl. But for the people that are really a part of the gym, it isn't an issue. The main problem is that most the guys are bigger than me, so sometimes it is hard to find training partners my size."

The women in our study generally felt they were accorded the same treatment and respect as men (with many attaining major roles in the gym as fighters, owners, and coaches). Still, they did acknowledge that their gender could be a source of stress in the external presentation of the activity. Specifically, the women fighters in our study continually mentioned that when fighting in front of a crowd, they felt that their performance reflected not only the sport but also the right to a woman's place in it. Shana, who in addition to being a medical student was a well known professional female fighter, made this point quite eloquently:

You get more people who still are not sold on the idea. [They say things like] "I don't want to watch women fighting," or "women shouldn't be fighting," or something like that. And I think it's frustrating seeing people with those sorts of views. Basically, I just try to ignore it. Not everyone is going to like female MMA, in the same way not everyone is going to like MMA full stop. But when you hear things like that, you sort of, um, there's a feeling you don't want to give them ammunition. You don't want to have a bad fight, and then have people turn around and say "see, women can't fight." I do feel a lot of pressure, you know... I do feel like I've got something to prove on that front.

The problem was not seen as the distinctions around gender within the subculture of fighters, but rather outside when dealing with spectators.

Our point here is not that gender is absent in the cage-fighting subculture, or even at the level of the local gym where discourse on meritocracy is the organizing principle. Indeed, fighters and gym owners are keenly aware that the world of MMA, like boxing or football, is largely populated by males. The topic of masculinity is present and visibly referenced in the public discourse. "Ring-girls" are almost always selected to walk around the cage or ring in bikinis between rounds because promoters feel this will appeal to the audience (even when the fighters are female). Still, as an explanatory framework, gender alone is not adequate for understanding the meanings and motivations associated with participating in MMA.

The moral world that members of the subculture espouse has little to do explicitly with masculinity, and much to do with ideas of meritocracy. As sociologists have long argued, the ubiquitous framework of meritocracy itself obfuscates and normalizes the underlying distinctions and inequalities on which it is based (Fischer et al. 1996). In cage-fighting, the ideology of meritocracy does not recognize that the very opportunity to "put in the work" in a largely male physical setting is at least partly mediated by factors such as class and gender, including a gendered division of labor in the world outside. It is much easier for men to "put in the work" as they are typically physically larger, less likely to have caregiving responsibilities at home, and less stigmatized if they show up at work with a black 
eye than their female counterparts. ${ }^{14}$ While one's sex does not determine position, role, or status within the cage-fighting subculture, it does influence other characteristics (such as free time and physique) that affect a fighter's ability to participate and climb the ranks. Still, explanations that try to explain the appeal of this subculture as a hyper-aggressive and exclusively-male enclave overlook the way that male and female fighters make sense of and experience this activity (Photograph 5).

\section{Violence and Social Regression}

We now turn to the notion that the appeal of this subculture is found in its tolerance and celebration of violence. It is understandable why cultural critics might posit that cagefighting is part of an insidious intrusion and expansion of violence into modern society. The image of men or women fighting in a cage, exchanging blows in a bloody tussle on the ground, certainly presents a dramatic image. Further, the early marketing of events like the Ultimate Fighting Championship, which trumpeted the event as a series of no-holds-barred fights, did little to counteract this narrative. Many fighters dislike the cage-fighting label, and argue that it perpetuates this stereotype. When we mentioned the term to a coach once he angrily remarked, "people have got to stop calling this cage-fighting. It is bad for the image of the sport" (we detail the reasons for our use of this term in our article under endnote 3). If we were to simply look at the aesthetics and presentation of this activity as a rhetorician or cultural critic might, we might be inclined to see violence and socialregression as well. However, much of the explanatory power for this line of inquiry is based on a simple analytical error. It is a misreading in which analysts conflate fighters with fans and aesthetics with meaning. Such accounts uncritically assume that the motivations that drive the casual fan to watch men or women fight in a cage are the same as those that drive fighters to spend 20 to 30 hours a week in the gym.

Clifford Geertz eloquently showed that any "thick description" of social life must go beyond purely behavioral accounts to look not just at the appearance of social action, but the webs of meaning that underpin them and give them context. Even seemingly straightforward events cannot be taken at face value. To be understood, the researcher must look at the symbolic world its participants inhabit (Geertz 2000a [1972], 2000c [1973]). In the same vein, to understand why people participate in mixed-martial-arts requires us to sideline assumptions about the aesthetics of the cage and to search for the systems of meanings that undergird human action (Durkheim 1984 [1893]; Taylor 1985; Weber 1978 [1925]).

When we looked at the "collective dispositions" and espoused understandings of this activity (Wacquant 1995a, b), it became impossible to sustain the argument that the subcultural world of the cage-fighter is about celebrating and supporting violence (Sammons 1988; van Bottenburg and Heilbron 2006). ${ }^{15}$ To the contrary, fighters downplay the violence and highlight the difficulty, competition, strategy, and challenge of fighting, often referring to it as a game of chess. As Mark, a 30-year-old man working in the entertainment industry, noted, "You have to set up all of your moves in advance. You can't

\footnotetext{
${ }^{14}$ Further, the social distribution of tastes, dispositions, and lifestyles, are underwritten by inequalities, and affect the ability of given individuals to successfully participate (Wacquant 2004; Wheaton 2004, 2007).

${ }^{15}$ We believe the notion that combat sports are somehow about the embrace of homoeroticism also falls into the category of explanations that involve imputing motivations to participants based on aesthetics. If the fight is a homoerotic ritual as some suggest (i.e. Wacquant 2004), it is not discussed as such by participants. Examining hidden motivations, micro-analyzing semiotics, and employing psychoanalysis, are outside of the purview of this study.
} 

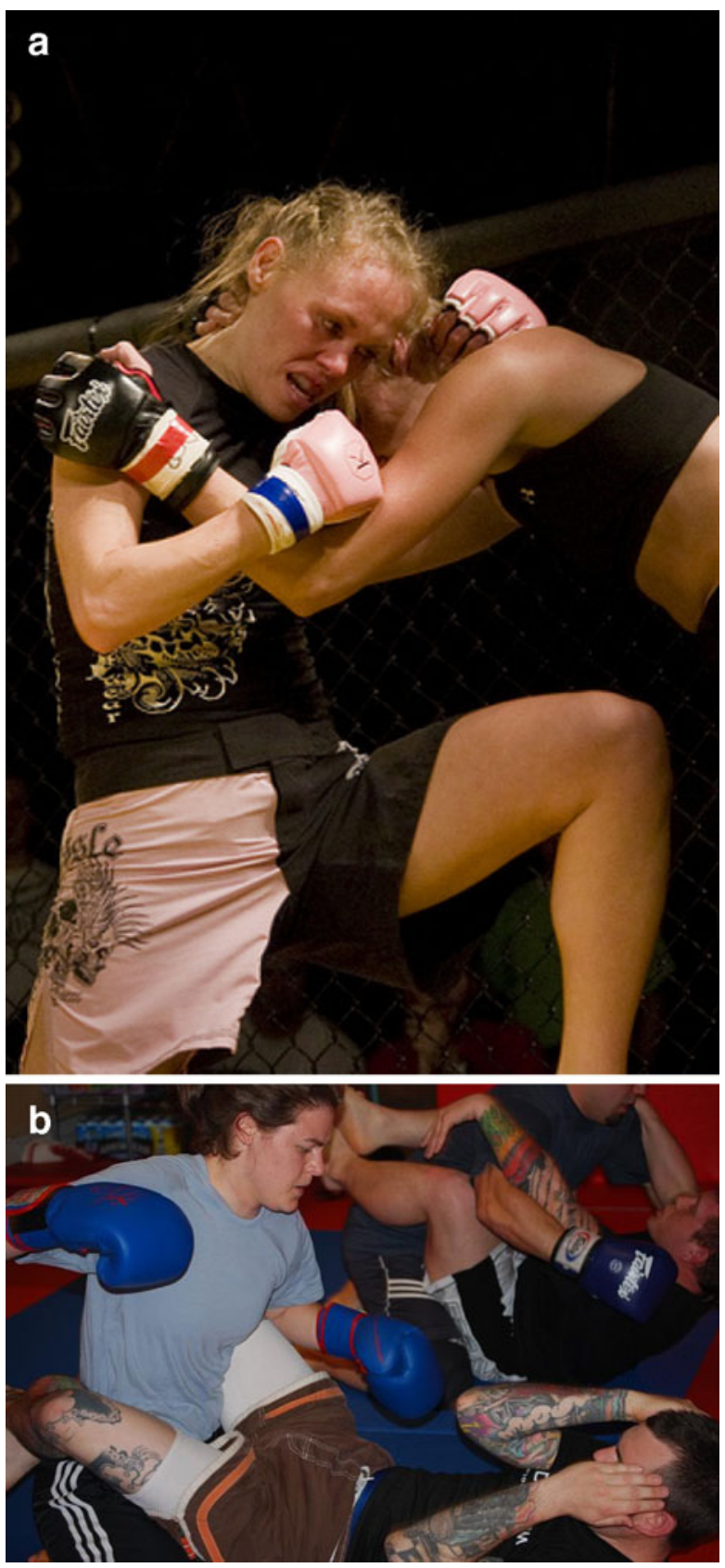

Photographs 5 Women fighting and training in mixed-martial-arts. Photograph a by Mike Bitton, Photograph b by Lily Pagle 
just play a move at a time; you can't say I'm just going to knock this guy out.... think that it [MMA] is a chess match and the guys that can set up those moves win."16

Joy in hurting others, fighting out of anger, or fighting outside of the cage, is looked down upon by most middle-class cage-fighters (see Wacquant 1995b for a similar finding among boxers). The individuals in our study see mixed-martial-arts as a sport: codified, regulated, and with specific victory conditions (Guttmann 2004). If they have to hurt their opponent to win, they do so, but this is not the espoused appeal of the activity. According to fighters, damaging one's opponent, like being injured, is a necessary "part of the game." It is not however, the primary appeal of that game.

Contrary to popular conceptions, violence in cage-fighting is tolerated rather than celebrated by fighters. Like other contact sports, mixed-martial-arts provides a special rulebound arena of social life wherein particular prohibitions and taboos can be collectively ignored for a time (Bredemeier and Shields 1986; Smelser 1999). The fight is a prime instance of "contextual morality" (Bredemeier and Shields 1986). Individual actors are freed from normal sanctions regarding hurting others because the acts of aggression and violence they commit are contained within a consensual, rule-bound system. As an experienced fighter in our study pointed out to a young competitor about to enter the cage for the first time, "Look, this is a gentleman's sport, and there's been an agreement made between the two of you. This isn't a street fight, you've both agreed to the rules, and to be there, and you need to know that. Go after him." If it is "violence," it is a peculiar form of codified, agreed upon, and "controlled violence" (Wacquant 2004).

In the world of cage-fighting, the fight is the primary public ritual (Photograph 6). Here, the taboo on deliberately injuring another member of the community is transgressed by two participants, to put on a performance that publicly reaffirms where individuals and gyms are ranked in the world of cage-fighting, and to demonstrate (through congratulations and hugging afterwards) they are all part of the moral community. The experience of the fight is intense. As John, the 31-year-old holistic health practitioner noted, "It is terrifying, exhilarating, exhausting, and painful. It's hard to put into words. It's sped up and put into slow motion at the same time." The fight serves as an integrative rite that fuses the moral world and status system in a way that makes it seem uniquely meaningful (Geertz 2000b [1966]). Meanwhile, the crowd - often discounted in the backstage speech of fightersserves to reaffirm the boundary between the fighters and pedestrians, and adds to the "collective effervescence" of the whole affair (Durkheim 1995 [1912]).

Fighters repeatedly invoke the distinction between a sportive contest that may potentially involve hurting an opponent or being injured, and what they see as true violence - an attempt to hurt or kill people out of animosity, anger, for instrumental gain, or duty (Wacquant 1995a, b, 2004). The following quotations are indicative of this distinction:

Abe, a 36-year-old gym owner with a degree in biology, stated: "Violent? You think of violence and you think of people who are angry, that are shooting each other or trying to hurt each other out of spite or anger. There's no anger involved in this. There is no animosity between fighters."

\footnotetext{
${ }^{16}$ In an interview in Mayeda and Ching's book (2008), Jason Miller, a professional fighter eloquently notes: "I didn't get into this sport for the chance to beat someone up without going to jail. I entered into this sport for the skill, for the challenge and brains it takes to succeed in the arena of combat. The allure of playing the now clichéd 'Ultimate Game of Chess' was much too strong for me to pass up. If boxing is the 'sweet science,' then mixed martial arts must be considered quantum physics" (Miller in Mayeda and Ching 2008, p. vii).
} 


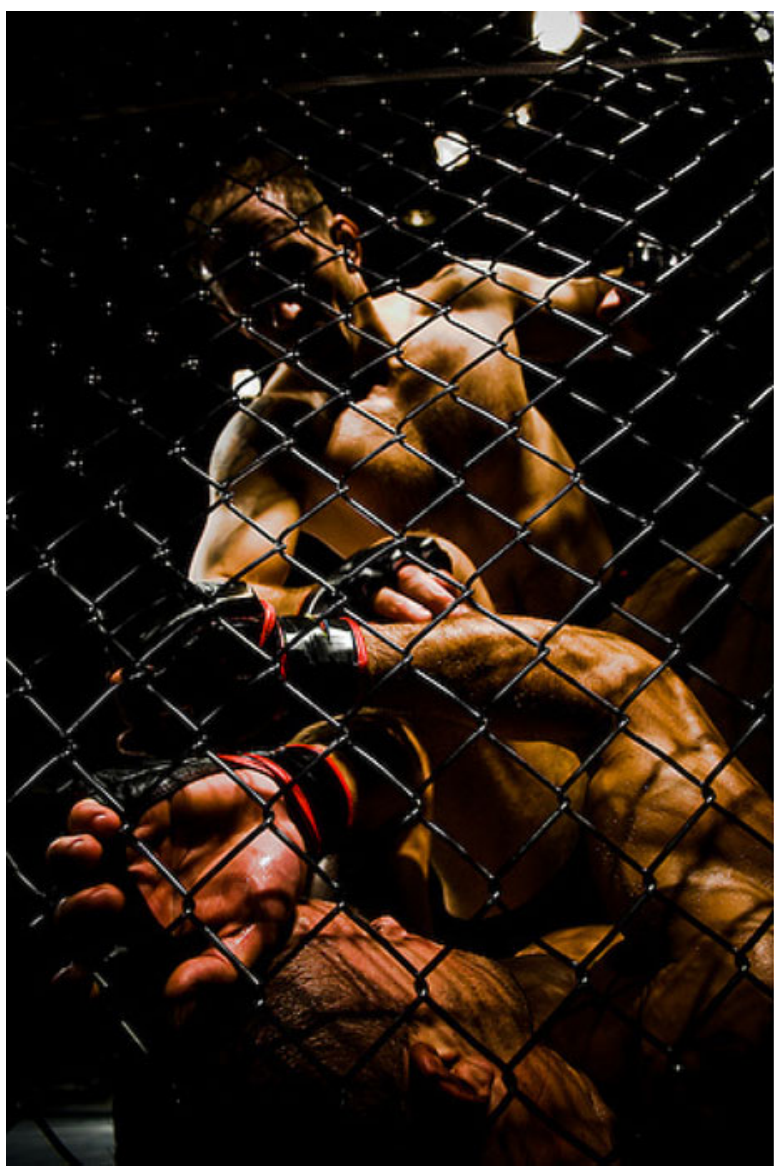

Photograph 6 The stark aesthetics of the fight. Photograph by Stefan Tell

Before stepping into a cage in front of 2,000 people, Bob, a 28 -year-old veteran of the second Iraq war, noted: “This [MMA] isn't a fight. This is a sport. Dragging your buddy through the streets of Baghdad, getting shot at, is a fight. This is an athletic competition."

In the gym, the norm against acting out on "violent" impulses is even stronger. Trying to seriously hurt training partners in the gym is considered an egregious breech of accepted behavior, which typically results in the transgressor being banned from the gym (see Donnelly 2004; Smith 2008b for similar findings).

This is not to say violence or bloodshed does not explain much of the appeal of the sport for a portion of the large American audience. Simply put, the forces that draw spectators to watch this activity are beyond the empirical scope of this article. While the fighters acknowledge that casual spectators are important to the growth of the sport and may eventually lead to larger paydays and more opportunities, they hold them in a certain amount of disdain much like the jazz musicians in Becker's classic study often held contempt for their patrons (Becker 1963). After a hard practice, Ken, the 31-year-old medical administrator, poignantly remarked to a fellow gym member: "The fans are idiots. They just want to see blood. That's not what this sport is really about..." This comment 
was met with a silent nod. Fighters believe that only those immersed in the subculture can understand what being a fighter is really about. Fans may fill the arena, but they are not seen as truly fit to judge members of the cage-fighting subculture.

To conflate the motivations of the throngs of fans with the motivations of fighters is to make a fundamental analytic error. To confuse the aesthetics of a "cage-fight" with the meaningful actions of participants is a second analytic error. We must conclude that the explanations that argue the primary appeal of the subculture is its counter-cultural embrace of violence, like those that place the primary appeal in strictly gendered terms, are sociologically inadequate. We now turn to why these middle-class individuals seek sociability in such an unlikely venue.

\section{The General Appeal of Voluntary Subcultures}

We have demonstrated that fighters do not collectively make sense of their trade in a way that emphasizes a desire to engage in violence or to overtly exert masculinity. In the following sections we will show that for its middle-class participants, mixed-martial-arts is seen as a shared activity that allows them to create a social space where they feel known and valued, and where the deeply held ideals that make up their moral world can be realized rather than thwarted. Our argument is not that the underlying ideals of this subculture are unique. Notions of meritocracy, authenticity, and voluntary community are deeply embedded and widespread elements of middle-class American morality. ${ }^{17}$ The draw for participants in this subculture lies in the perceived concordance between these shared ideals and their realization in the form of the subculture's micro-status system. They feel that other spheres of their life (e.g. the world of work) do not offer this match. This sense of concordance is enhanced by the embodied and visceral nature of subcultural rituals in the world of cage-fighting, which range from the omnipresent conditioning of the body to the intensity of the fight. These rituals reaffirm and reinforce the subculture's ideals as part of the participants' habitus. Underlying ideals are understood as something meaningful and important (Atkinson 2008; Bourdieu 1984; Geertz 2000b [1966]; Wacquant 2004). As Michelle, a 29-year-old teacher, noted:

I sometimes compare the training to churches. I mean, I'm not a religious person, but in spirit. If you look at the way a church functions, it's a collective, it's a place where people gather because they share a common belief and they want to feel good about those beliefs.

Middle-class fighters make sacrifices in other elements of their lives because the perceived concordance between ideal and practice in MMA, heightened by the intense experiences of training and competing, makes it seem uniquely meaningful and true (see Geertz 2000b [1966]). When Adam, a 31-year-old graduate student, was asked why MMA was so important he responded, "It's going to be tough to describe, to articulate, but I think it was the purity of it [cage-fighting]. It eliminated all the bullshit."

\section{Charting the Moral World}

The moral world that underpins the subculture created by cage-fighters has three key elements. The first is self-improvement through hard work; the second is "being true to

\footnotetext{
${ }^{17}$ These ideals are often shared in other social strata as well (e.g. Liebow 1967) and may be common in other Western societies, but they are irreducible here because they form a core element of the American middle-class belief system.
} 
yourself"; and the third is constructing a voluntary community. We now turn to each of these in detail.

\section{Self-Improvement as the Legitimate Route to Status: Constructing the Meritocratic-Self}

The notion of advancement through hard work and character, "pulling yourself up by your bootstraps," has long been a dominant discourse in the United States, even if its realization on a wide scale has been elusive (Fischer et al. 1996). Americans generally support the idea of meritocracy, the notion that where you end up in society should the result of your skills, talents, and dispositions rather than your social origin. Many feel that the inequalities of outcomes are reasonable, provided the playing field is fair and opportunities are equal. ${ }^{18}$ Not surprisingly, many find this ideal to be thwarted in everyday life. While this phenomenon is most often recognized by social scientists among those who do not have abundant opportunities in the social mainstream - such as the poor, minorities, or youth — we found this was true of the middle-class fighters in our study as well.

Despite having promising careers outside of the cage and a comfortable standard of living at home, the fighters in our study felt that their avenues for self-improvement were limited by factors out of their control. They consistently indicated that cage-fighting is so important to them because it allows self-improvement through hard work, providing a uniquely intense experience that was not available elsewhere. The individuals we studied did not reject the mainstream ideals of meritocracy, diligence, competition, and selfimprovement, but rather sought out a subculture that allowed them to feel that these ideals were realized. ${ }^{19}$ Jacob, a 27-year-old teacher, put it quite poignantly: "In MMA...you're trying to improve yourself, physically, mentally, and I'd say spiritually...and proving yourself amongst your peers through hard work (Photograph 7)."20

The middle-class fighters we studied saw training and competing in mixed-martial-arts as a way to build character and improve themselves through discipline, hard work, and sacrifice. Training in the gym was understood as the way to realize these ideals. They felt cage-fighting gave them the chance to construct the "self" they wanted to be (Fine and Kleinman 1979), whereas other spheres of their life like work did not. They felt their position in the world of MMA was the result of their efforts directed towards being the sort of person they wanted to be, whereas their positions outside of MMA were not. As Jim, the 22-year-old nurse put it,

The respect I earn from them [the other guys in the gym] means more to me than the respect I earn at work. In the gym my value lies in my ability to be tough and to suffer and to keep on going regardless of how miserable the conditions are and improve myself, whereas [at work] my value and stock lies in my ability to put a

\footnotetext{
${ }^{18}$ For an example of a proponent see Murray (1984); for sociological critiques see Arrow et al. (2000), Fischer et al. (1996), and Lemann (1999).

${ }^{19}$ Stratton (1985) comments on a similar phenomenon among the working-class subcultures of American bikers and surfers, both of which accept key elements of American ideology.

${ }^{20}$ Pro fighter Dave Menne offers a similar quote: "There's an amount of freedom from it, a certain kind of reward that doesn't always occur in everyday life. A lot of times it's a matter of who you know, or who your dad knows. In our sport, it is what you accomplish. You just have to weather the storm. Sometimes it's a battle of attrition, but you can always be a master of your destiny" (Dave Menne, quoted in Krauss and Bret 2002, p. 263).
} 


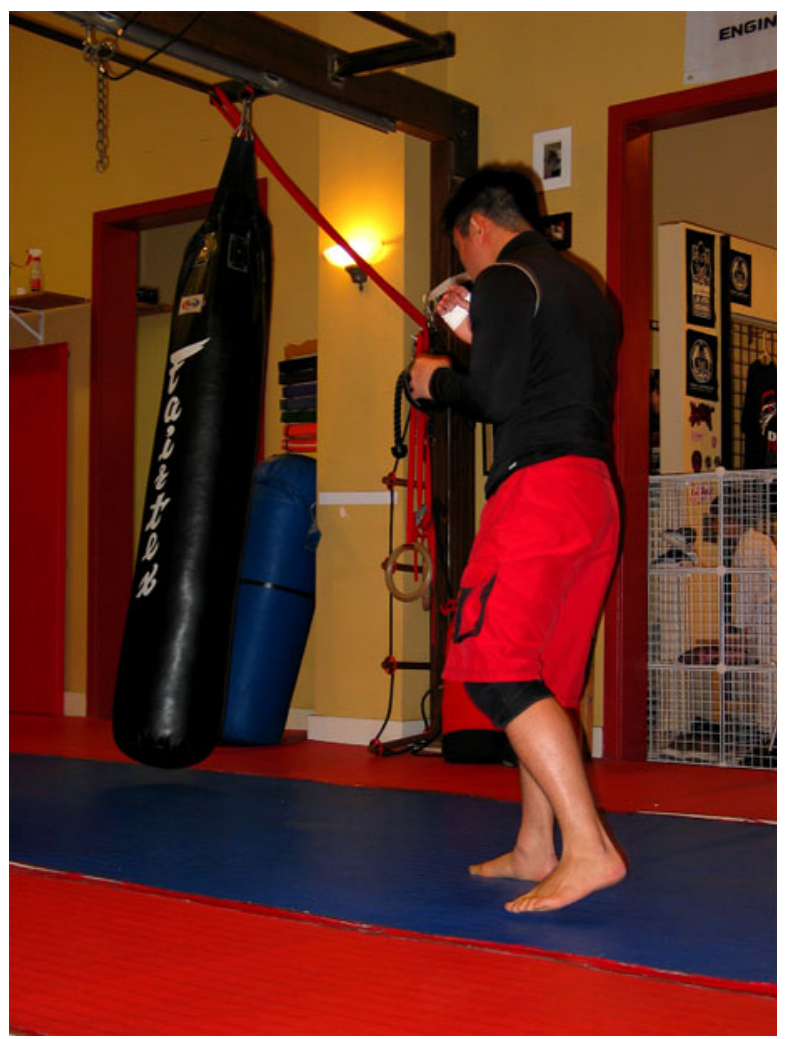

Photograph 7 Working the bag after practice. Photograph by Corey M. Abramson

smile on my face when someone is being an asshole to me. I don't really care too much about that. ${ }^{21}$

Self-improvement through determination and rigorous effort is the ideal in the moral world of our subjects, and its perceived realization is rewarded with status in the subculture (see also Atkinson 2008). But every ideal has its negative counterpoint. In cage-fighting, the negative case is exemplified by fighters who are lazy; those who are not willing to "put in the work." Individuals who come into fights out of shape or do not spend time improving technical weaknesses are seen as disappointments or embarrassments to themselves and their home gyms. Sitting backstage at an amateur event we overheard one fighter make a critical remark about a teammate to his coach:

Three fucking minutes, and his hands are on his knees? He was walking away from the other guy? He obviously wasn't doing the conditioning he told us he was doing. I'm fucking embarrassed. See if I train with him again.

\footnotetext{
${ }^{21}$ Here the desire to avoid façades, and the emotional labor required in face-to-face interaction is palpable (Hochschild 2003). This is also very similar to the quote offered by one of Atkinson's (2008, p. 304) triathletes, "At work I'm a name on the door, or at the bottom of a page, but in a race, it's just me, my body and the elements. Whatever I've lived through that day, it's because I stuck it out and pushed the limits." (Atkinson 2008, p. 304)
} 
At that same event, the critic above complimented another gym mate on a hard fought but definitive loss by knockout. When fighters are perceived as lazy rather than industrious, their position in the subculture suffers even if they win. Fighters are acknowledged for their hard work and "heart" even if they lose. It is not that performance or victory do not matter, but that particular elements of performance associated with revealing the "true self" (e.g. showing heart), which are inscribed with moral significance, trump other considerations. ${ }^{22}$ As Shana, the 32-year-old medical student notes, the most important thing about fighting "is about getting in there and giving it your all under whatever circumstances you find it".

\section{Fighting as a Sphere of Authenticity: Revealing the True Self}

If part of the appeal of cage-fighting for participants is the belief that the gym allows them to construct and shape their character, an equally important part of the appeal stems from the belief that fighting in a cage can reveal one's character. The notion of authenticity, or being true to one's character in the face of adversity, features prominently in the moral world of our fighters (see also Birrell 1981; Sheridan 2007). ${ }^{23}$ The overarching principle is that each individual has a "true self" that can be revealed under pressure. Fighters believe that each person can act in a way that is either in accordance with that self (authentic action) or not (inauthentic action). ${ }^{24}$ Participants described fighting as an activity that allows them the opportunity to explore and express the essence of their character, show "who they really are," and to have others who matter recognize this. MMA is not just seen as an avenue for self-improvement, but as an activity that strips an individual's character bare. This was exceedingly important to those in our study:

Abe, the 36-year-old gym owner: "When you step into the ring, you see who you are. It's just you and another guy. All the bullshit is stripped away. You find out about yourself, man. You see who you are."

John, the 31-year-old holistic health practitioner: "MMA is a place where I can challenge myself more than any other place in my life....It's more of a self test than a test of skill."

As the statements above demonstrate, the individuals in our study purport that fighting reveals the true self, and allows this to be known to others. In the cage or ring, fighters confront the pressure of an opponent, as well as the spectators. The trial of the cage presents an "action situation" in Goffman's (1967) sense. It is a setting in which an individual must confront a potentially embarrassing or negative outcome such as being bested or revealed as a coward. By, "standing correct and steady in the face of sudden pressure," (Goffman 1967, p. 217) fighters show themselves and their peers who they really are by reaffirming collectively recognized virtues such as gameness, heart,

\footnotetext{
${ }^{22}$ Of course this may not hold true at the highest levels of the sport, where paydays are based on winning. But at the lower and middle levels, this appears to be the case.

${ }^{23}$ While the notions of essentialist individualism and authenticity are both deeply problematic from a philosophical and empirical perspective, a critique of the underlying cultural logics and their deployment goes beyond the scope of his article.

${ }^{24}$ Note that this notion of an authentic self is related to, but not synonymous with, notions of the authenticity of subcultural products (see Thornton 1996).
} 
courage, and asceticism (Birrell 1981). Fighters believe training in the gym is about becoming the sort of person you want to be, and fighting in front of an audience is about revealing who you are and who you have become, both to yourself and to everyone watching.

Fighters feel cage-fighting does this better than other sports or activities because of the intensity of the experience and the lack of mediating factors such as excessive rules or equipment (e.g. a ball, racquet, protective gear, etc.). This translates into an intense experience that solidifies the belief that this is a unique test of character that is unavailable elsewhere. When asked why she fights, Shana, 32-year-old medical student, presented her response in a systematic way:

I think I can answer that on a few different levels. I mean on one level it's the challenge; it's something I enjoy doing. It's mental, it's physical, it's emotional. It's got components of all those different areas and the technical aspect's huge. Physically I'm in the best shape of my life and the whole you know, dealing with pressure, sports psychology. I'm an emotional fighter which I also find really interesting and bringing that all together and putting it together under pressure in that environment, I just find that a really exciting challenge. That's one aspect to it. Then on another side, and the reason I got into it in the first place was to find out whether I could fight, and I think this sort of thing has nothing to do about fighting. (emphasis added)

It is important to recognize that the "winning is everything" attitude that often dominates in other sports does not hold as much sway in the world of the middle-class mixed-martialartist, at least not at the amateur and lower professional levels (Messner 1995). Winning is important and every athlete who we watched compete wanted to win, but most said something similar to Jacob, the 27-year-old teacher, when he commented, "win or lose, I learn something about myself, as long as I lay it on the line, I'm happy." Sacrificing their bodies, giving their all, enduring pain, and putting on a "good show" were lauded as ideals (Atkinson 2008; Smith 2008a, b).

The negative counterpoint to putting it all on the line for the fighters in our study was to "play for points." Fighters that appeal to the cage-side judges' scorecard in order to win by decision, as opposed to making every effort within their control to end a fight, were looked down upon. While at the highest levels, fights and title shots are ostensibly determined by win-loss records, this normative script of "giving it all" still reigns. Kenny Florian, a lightweight UFC contender, made this point while publicly defaming the current champion: "I finish fights! I don't just try to win, I finish fights!" 25 Simply put, winning is not regarded as highly as putting it "all on the line."

\section{Voluntary Community as Purity: Forging a Subculture with Other True Selves}

Underwriting the subculture of cagefighting is the notion of a voluntary community - a group of people who come together of their own volition, in the presence of other likeminded individuals (Bellah et al. 2007; de Tocqueville 2003). We have already shown that the people in this subculture draw a strong distinction between fighters and everyone

${ }^{25}$ Public comments after a first round stoppage of Alvin Robinson at UFC 73 on July 7, 2007 at Arco Arena in Sacramento, $\mathrm{Ca}$. 
else. Fighters are seen as special, different, and morally superior. They feel that through their sacrifices and actions, they have demonstrated their worth and earned their spot in the community. Abe, the 36-year-old gym owner, put it most clearly and forcefully when he said, "When I walk into a room, I think I am better than everybody else because I do this. If you fight, you're a different kind of person. You've challenged yourself in a way most people can't." This connection is forged "through shared rites and intense physical and emotional passage" (Atkinson 2008, p. 306) such as grueling training sessions, a strict diet, and the ritual of the fight itself. Mark, a 30-year-old working in the entertainment industry, noted, being a fighter "means you've chosen to do something that most people can't. Most would, but couldn't. That may be an egotistical thing to say, but it's definitely a separation between fighters and non-fighters." As Adam, the 31-year-old graduate student, noted "They [fighters] have made a choice to do something very unique. They've accepted a lot of pain, and accepted a lot of physical hardships and it's very voluntary....How many other people want to spend a Saturday morning getting punched in the face?"

This distinction between the fighter and gym member-who are seen as special—versus everybody else is an integral part of the system of moral boundaries that demarcates subcultures (Becker 1963; Thornton 1996; Lamont 2000). The subculture of fighters exists by an active process of "construct[ing] similarities and differences between themselves and others" (Lamont 2000, p. 3). The categories of participant and fan, like those of hip and square (Becker 1963; Thornton 1996), are not held to be equal in the minds of those we studied. They have strong normative content as one is seen as clearly better than the other (Lamont 2000; Wacquant 2004) (Photograph 8).

The fighters in our study believed only those who have gone through the trials and tribulations that build and reveal character can accurately judge another member of the MMA community. Therefore, what peers inside the subculture think may be more important than what those outside it think. As Ken, the 31-year-old medical administrator, describes it:

People in the gym are more important to me than people outside of it, friends at work, you know, because [gym members] are part of the team. When I get compliments at the gym, this is what I'm really passionate about...they know what I put in.

As another fighter noted in practice, "The gym is my home. These guys are my family."

Members of the subculture believe that people who can train and fight whether they are men or women, winners or losers, are considered part of the MMA community and are afforded respect according to its standards of hard work, self-improvement, and authenticity. As Adam, the 31-year-old graduate student, noted, "Even guys that aren't physically talented are good guys. They're contributing to the atmosphere of the gym, and keeping things moving." Individuals not willing to undergo its trials are excluded from the subculture.

In the world of cage-fighting the ideal fighter is someone who is willing to learn from anyone: big or small, man or woman. Fighters must work hard on improving and be dedicated to developing their craft. As the individuals in our study continually pointed out, if a person does not possess these characteristics, it is difficult for them to be become a fullfledged member of the group. Fighters often recounted stories about the many people who enter cage-fighting gyms only to leave them a short time later. The ones who stay, they 

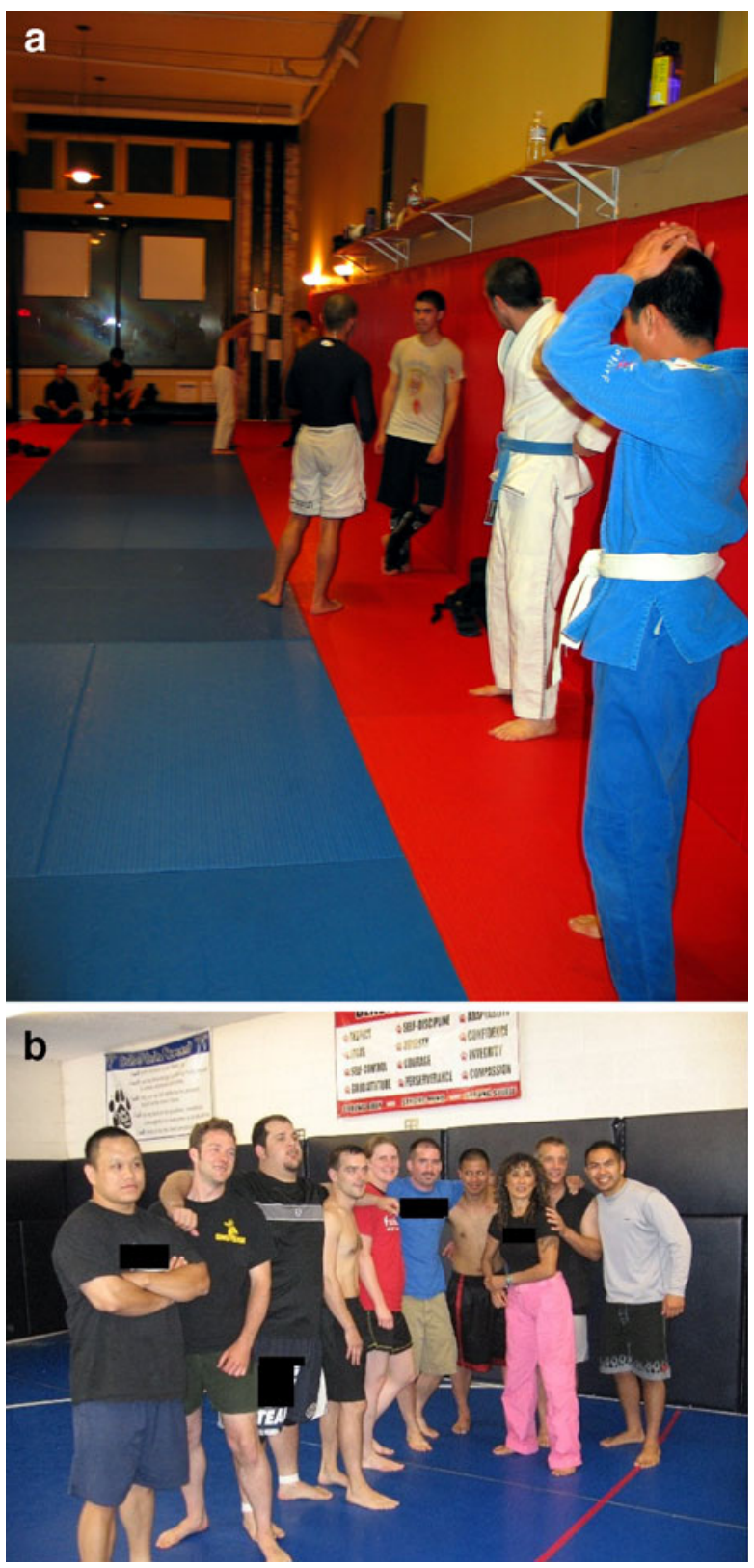

Photograph 8 The Voluntary community after practice (photograph a) and inter-gym fights (photograph b). Corey M. Abramson is pictured third from the left in the final picture. Photograph a by Corey M. Abramson. Photograph b by Gabriela Vargas-Bazan

point out are the ones that can "check their egos at the door." Jacob, the 27-year-old teacher, stated he had seen many people want to train:

Thinking they're bad because they've been in a few street fights or they are Marines, or whatever. But unless they're willing to get tapped [yield to a submission hold] six 
ways from Sunday by the littlest dude in our gym and learn from that, they leave; their egos can't handle it. And honestly, we don't want them here.

Being part of the subculture means submitting not only to the ideals of the subculture, but to its status hierarchies and authorities. ${ }^{26}$

\section{A Note on Inequality}

The organizing principles of a meritocratic and voluntary community, open to all who put in the work, like the associated notions of authenticity, and self improvement, inevitably mask the inequalities in race, class, and gender that allow some people the opportunity to participate in a subculture when others cannot (Wheaton 2004, 2007). Seemingly objective criteria of merit are often based upon and reaffirm social distinctions and inequalities (Bourdieu 1984). While the members of the subculture we observed were consistent in not rejecting people based on race, class, or gender, it is hard to deny the fact that this subculture is rooted in specific ideals, institutions, and morality. Members of the subculture are not likely to acknowledge that being a successful member of this subculture requires significant leisure time, athletic ability, material resources, and cultural dispositions (Fletcher 2008; Wacquant 2004). It is based upon, inculcates, and validates the privileged tastes and dispositions of the middle-class (Atkinson 2008; Bourdieu 1984; Donnelly and Harvey 2007; Wacquant 2004). The notion of meritocracy is meaningful to participants, but, as in society proper, it obscures the myriad inequalities that are not part of the subculture's collective self-presentation.

\section{Conclusions}

This article began with a theoretical conundrum: sociological understandings of subculture are disproportionately concerned with, and based upon, those at society's margins. While post CCCS theorists have explored the lifestyles and scenes of the middle-class, definitive statements on the draw and function of subcultures remain elusive. The result is a set of lopsided theories that miss much of what is important for subcultures at all levels of systems of stratification. We examined the subculture of middle-class American cagefighters to explore this issue. We began by examining a concrete puzzle, which previous theories have had trouble explaining: why do middle-class individuals, with ready access to conventional avenues of success and status, participate in the world of cage-fighting despite a number of bodily, interpersonal, and professional sacrifices?

We found that fighters are drawn to the cage-fighting subculture because they feel it gives them visceral access to widespread American ideals, such as being rewarded for hard work, "being true to oneself," and forming voluntary communities. Our argument is not that the ideals of the cage-fighting subculture are unique or novel, but rather that they comprise widely shared, constituent elements of middle-class morality and habitus. Despite its exceptional appearance, and the intensity and seeming peculiarity of its rituals, the underlying morality of this subculture is "scarcely different than the social psychology of the ideal typical middle-class life" (Atkinson 2008, p. 309). Fighters feel the local status systems created in the gym and supported by their pugilistic peers, better reflect who they

\footnotetext{
${ }^{26}$ In many cases, those who do not submit to the authority structure of the gym are physically "put in line" by more experienced fighters to humble them.
} 
"really are" and who they "want to be," than their positions in society proper. Participation becomes an organizing principle of life, one that assumes great importance through the powerful draw associated with a perceived match between ideals and practice. This sense of concordance fused in both extraordinary and mundane rituals (Durkheim 1984 [1893]; Goffman 1963), makes the resulting activity seem uniquely real and meaningful (Geertz 2000b [1966]). In the end, the world of cage-fighting uses seemingly strange practices to inculcate and reaffirm the widely held American ideals on which it is based (Atkinson 2008; Bourdieu 1984; Wacquant 2004). ${ }^{27}$

The case we studied is important in the challenge it poses to the prevailing wisdom about why people, particularly those with access to conventional success, participate in subcultures. By examining the world of the middle-class cage-fighter, we explored a case that previous theories of subculture have difficulty explaining, and illustrated the way many of these issues look on the ground level of social life. We went beyond an exclusive focus on the constraints, negative determinants, and problems of objective adjustment (Cohen 1955 ) that funnel people into a subculture, and looked at the positive attractions that explain much of its appeal (Wacquant 1995b).

In this vein, this article makes three key contributions to the existing literature on subculture, morality, and sociability, each of which has implications for future studies:

(1) First, scholars must pay serious attention to the positive appeal of subcultures, and to their pull on members. These include the subjective and affective dimensions of membership. The middle-class individuals in our study whole-heartedly participated in the world of cage-fighting, despite the difficulties, tensions, and sacrifices that participation entailed. The fact that people at all levels of society participate in subcultures strongly suggests that subcultural participation is not simply an artifact of systems of exclusion, but rather a combination of exclusion and appeal. We showed that this appeal is particularly strong when participants feel there is a subjective concordance between belief and practice. Theories of subculture need to be attentive to the way systems of stratification affect the material and cultural resources that enable and constrain actions, tastes, dispositions, and motivations, and consequently the available forms of sociability (Bourdieu 1984; Swidler 2000; Sewell 1992). Still, to focus only on how those who are marginalized or deviant are sorted or pushed into subcultures misses a great deal of the nuances of both micro- and macro-stratification, and much of what is important about these unique bounded social worlds. Doing this overlooks much of the positive draw of subculture for those who are socially marginalized (Wacquant 1995b; 2004), the forms of restraint that affect those who are not (Fletcher 2008), and the myriad and subtle ways these are based upon and reinforce existing inequalities.

(2) The people in our study did not reject conventional American ideals. The ideals of a subculture need not be novel or resistant to have force in the lives of its members. In fact, much of the appeal of the subculture was that they felt deeply held American ideals, such as the belief in self-improvement, authenticity, and voluntary community, were more viscerally realized in the world of cage-fighting than outside. The appeal of comparatively volitional subcultures does not necessarily come from the ability to furnish an alternative morality, but from the feeling that ideals and practices are not at

\footnotetext{
${ }^{27}$ In a sense, Cohen (1955) may have been right when he framed subcultures as a solution to problems of adjustment. In the case of middle-class subcultures, however, the problem of adjustment is not an objective inability to fit into society's roles, but a subjective discordance between ideals and their implementation.
} 
odds with each other. Often, the implicit critique leveled against society at large is not of the underlying ideals upon which the middle-class lifeworld is based, but rather in their implementation.

(3) Finally, while pundits, academics, and cultural critics have lambasted cage-fighting as the worst modern society has to offer - a form of asocial devolution - it is a classic example of American community. The irony is that much of the appeal of an activity that has been decried for using violence to divisively appeal to the worst in human nature lies in its ability to facilitate the construction of a voluntary-community in a seemingly unlikely place. Social scientific nay-sayers who lament the decline of American social connectedness (e.g. Putnam 2000) should consider that even those subcultures located on the fringe of acceptability can be an important point of sociability that ultimately reaffirm widely held ideals - and the inequalities and contradictions these encapsulate.

Acknowledgements We would like to thank Martín Sánchez-Jankowski, Ann Swidler, Loïc Wacquant, Phillip Fucella, Greggor Mattson, Gretchen Purser, Manata Hashemi, Silvia Pasquetti, Kathleen Marker, Neil Gong, the editors of Qualitative Sociology, and three anonymous reviewers, for helpful comments on previous drafts of this article. We would also like to thank the research assistants whose hard work greatly aided this project. Any remaining errors or inconsistencies in this article are our own. Finally, we would like to acknowledge funding by the Jacob K. Javits program, the Inequality by Design mini-grant program, UC Berkeley, and the Center for the Study for Social Change whose financial support made this research possible.

Open Access This article is distributed under the terms of the Creative Commons Attribution Noncommercial License which permits any noncommercial use, distribution, and reproduction in any medium, provided the original author(s) and source are credited.

\section{References}

Abramson, C. (2009). Who are the clients?: Goal displacement in an adult day care center for elders with dementia. International Journal of Aging \& Human Development, 68, 65-92.

Anderson, N. (1923). The hobo: The sociology of the homeless man. Chicago: University of Chicago Press. Arrow, K., Bowles, S., \& Durlauf, S. (Eds.). (2000). Meritocracy and economic inequality. Princeton: Princeton University Press.

Atkinson, M. (2008). Enduring bodies in triathlon. In K. Young \& M. Atkinson (Eds.), Tribal play: Subcultural journeys through sport, research in the sociology of sport (Vol. 4, pp. 295-317). Bingley: Emerald Group Publishing Limited.

Becker, H. (1963). Outsiders: Studies in the sociology of deviance. New York: The Free Press.

Bellah, R., Madsen, R., Sullivan, W., Swidler, A., \& Tipton, S. (2007). Habits of the heart: Individualism and commitment in American life. Berkeley: University of California Press.

Bennett, A. (1999). Subcultures or neo-tribes? Rethinking the relationship between youth, style and musical taste. Sociology, 33, 599-617.

Birrell, S. (1981). Sport as ritual: Interpretations from Durkheim to Goffman. Social Forces, 60, 354-376.

Bourdieu, P. (1984). Distinction: A social critique of the judgment of taste. Translated by R. Nice. Cambridge: Harvard University Press.

Bourdieu, P. (1990a). In other words: Essays toward a reflexive sociology. Stanford: Stanford University Press.

Bourdieu, P. (1990b). The logic of practice. Stanford: Stanford University Press.

Bredemeier, B., \& Shields, D. (1986). Athletic aggression: An issue of contextual morality. Sociology of Sport Journal, 3, 15-28.

Burawoy, M. (1998). The extended case method. Sociological Theory, 16, 4-33.

Butryn, T., \& deGaris, L. (2008). Johnny Rodz and the jade ring: Larry and Ted's excellent adventures in pro wrestling. In K. Young \& M. Atkinson (Eds.), Tribal play: Subcultural journeys through sport, research in the sociology of sport (Vol. 4, pp. 337-351). Bingley: Emerald Group Publishing Limited. 
Chaney, D. (1994). The cultural turn: Scene-setting essays on contemporary cultural history. London: Routledge.

Clarke, J., Hall, S., Jefferson, T., \& Roberts, B. (1976). Subcultures, cultures, and class. In S. Hall \& T. Jefferson (Eds.), Resistance through rituals: Youth subcultures in post-war Britain (pp. 9-75). London: Hutchinson.

Cloward, R., \& Ohlin, L. (1960). Delinquency and opportunity: A theory of delinquent gangs. New York: The Free Press.

Cohen, A. (1955). Delinquent boys: The culture of the gang. New York: The Free Press.

Cohen, S. (1972). Folk devils and moral panics: The creation of the Mods and Rockers. London: McGibbon Kee. Cressey, P. (1932). The taxi-dance hall. New York: Greenwood.

Crigger, K. (2008). Title shot: Into the shark tank of mixed-martial-arts. Auberry: Victory Belt.

de Tocqueville, A. (2003). Democracy in America. New York: Penguin Classics.

Derné, S. (1994). Cultural conceptions of human motivation and their significance for culture theory. In D. Crane (Ed.), The sociology of culture (pp. 267-287). Cambridge: Blackwell.

Dohan, D., \& Sanchez-Jankowski, M. (1998). Using computers to analyze ethnographic field data: Theoretical and practical considerations. Annual Review of Sociology, 24, 477-498.

Donnelly, P. (1981). Toward a definition of sport subcultures. In M. Hart \& S. Birrell (Eds.), Sport in sociocultural processes (3rd ed., pp. 565-587). Dubuque: Wm. C. Brown.

Donnelly, P. (1993). Subcultures in sport: Resilience and transformation. In G. Ingham \& J. Loy (Eds.), Sport in social development: Traditions, transitions, and transformations (pp. 119-147). Champaign: Human Kinetics.

Donnelly, P. (2004). Sport and risk culture. In K. Young (Ed.), Sporting bodies, damaged selves: Sociological studies of sports-related injury (pp. 29-57). New York: Elsevier.

Donnelly, P., \& Harvey, J. (2007). Class and gender: Intersections in sport and physical activity. In K. Young (Ed.), Sport and gender in Canada (pp. 119-147). Toronto: Oxford University Press.

Dunning, E. (1999). Sport matters: Sociological studies of sport, violence, and civilization. London: Routledge.

Durkheim, E. (1984 [1893]). The division of labor in society. New York: The Free Press.

Durkheim, E. (1995 [1912]). The elementary forms of religious life. New York: The Free Press.

Fine, A., \& Kleinman, S. (1979). Rethinking subculture: An interactionist analysis. The American Journal of Sociology, 85, 1-20.

Fischer, C. (1975). Toward a subcultural theory of urbanism. The American Journal of Sociology, 80, 1319-1341.

Fischer, C., Hout, M., Sánchez Jankowski, M., Lucas, S., Swidler, A., \& Voss, K. (1996). Inequality by design: Cracking the bell curve myth. Princeton: Princeton University Press.

Fletcher, R. (2008). Living on the edge: The appeal of risk sports for the professional middle-class. Sociology of Sport Journal, 25, 310-330.

Frith, S. (1983). Popular music: Critical concepts in media and cultural studies. London: Routledge.

Geertz, C. (2000a [1972]). Deep play: Notes on the Balinese cockfight. In C. Geertz (Ed.), The interpretation of cultures: Selected essays (pp. 412-453). New York: Basic Books.

Geertz, C. (2000b [1966]). Religion as a cultural system. In C. Geertz (Ed.), The interpretation of cultures: Selected essays (pp. 87-126). New York: Basic Book.

Geertz, C. (2000c [1973]). Thick description: Towards an interpretive theory of culture. In C. Geertz (Ed.), The interpretation of cultures: Selected essays (pp. 3-30). New York: Basic Books.

Gentry, C. (2001). No holds barred: Evolution, the truth behind the world's most misunderstood sport. Richardson: Archon.

Gibson, J. (1994). Warrior dreams: Violence and manhood in post-Vietnam America. New York: Hill \& Wang.

Goffman, E. (1963). Stigma: Notes on the management of spoiled identity. Englewood Cliffs: Prentice Hall.

Goffman, E. (1967). Where the action is. In E. Goffman (Ed.), Interaction ritual (pp. 149-270). Garden City: Anchor Books.

Gordon, M. (1947). The concept of subculture and its application. Journal of Social Forces, 26, 40-42.

Guttmann, A. (2004). From ritual to record: The nature of modern sports. New York: Columbia University Press.

Hebdige, D. (1981). Subculture: The meaning of style. London: Routledge.

Hochschild, A. R. (2003). The managed heart: Commercialization of human feeling, twentieth anniversary edition, With a new afterword. Berkeley: University of California Press.

Hopton, J. (2002). Combat sports: Validation of male violence or solution to a crisis of masculinity. Paper presented at the Gender, Sexuality, and the Law International Conference.

Hughson, J. (2008). "They think it's all over": Sport and the end of subculture debate. In K. Young \& M. Atkinson (Eds.), Tribal play: Subcultural journeys through sport, research in the sociology of sport (Vol. 4, pp. 49-66). Bingley: Emerald Group Publishing Limited.

Kahn-Harris, K. (2004). Extreme metal: Music and culture on the edge. Oxford: Berg. 
Krauss, E., \& Bret, A. (2002). Brawl: A behind-the-scenes look at mixed martial arts competition. Toronto: ECW.

Kreager, D. (2007). Unnecessary roughness? School sports, peer networks, and male adolescent violence. American Sociological Review, 72, 705-724.

Laitin, D. (1986). Hegemony and culture: Politics and religious change among the Yoruba. Chicago and London: University of Chicago Press.

Lamont, M. (2000). The dignity of working men: Morality and the boundaries of race, class, and immigration. Cambridge: Harvard University Press.

Lemann, N. (1999). The big test: The secret history of the American meritocracy. New York: Farrar, Straus and Giroux.

Liebow, E. (1967). Tally's corner: A study of Negro street corner men. Boston: Little, Brown.

Lubin, J. (2008). Mixed-martial-arts fighting its way into the mainstream. CNN.com. http://www.cnn.com/ 2008/LIVING/09/18/ultimate.fighting.championship/index.html. Accessed January 22, 2010.

MacLeod, J. (1987). Ain't no makin' it: Leveled aspirations in a low-income neighborhood. Boulder: Westfield.

Malcom, D., \& Velija, P. (2008). Female incursions into cricket's "male preserve." In K. Young \& M. Atkinson (Eds.), Tribal play: Subcultural journeys through sport, research in the sociology of sport (Vol. 4, pp. 217-234). Bingley: Emerald Group Publishing Limited.

Martin, K. (1998). Becoming a gendered body: Practices of preschools. American Sociological Review, 63, 494-511.

Martin, P. (2004). Culture, subculture and social organization. In A. Bennett \& K. Kahn-Harris (Eds.), After subculture: Critical studies in contemporary youth culture (pp. 21-35). New York: Palgrave.

Mayeda, D., \& Ching, D. (2008). Fighting for acceptance. New York: Universe Inc.

Messner, M. (1989). Masculinities and athletic careers. Gender and Society, 3, 71-88.

Messner, M. (1990). When bodies are weapons: Masculinity and violence in sport. Sociology of Sport Journal, 25, 203-218.

Messner, M. (1995). Power at play: Sports and the problem of masculinity. Boston: Beacon.

Messner, M. (2002). Taking the field: Women, men, and sports. Minneapolis: University of Minnesota Press.

Miles, S. (1998). Consumerism as a way of life. London: Page.

Mills, C. W. (1940). Situated action and vocabularies of motive. American Sociological Review, 5, 904-913.

MSNBC (2007). Warrior nation. Originally aired January 9-January 30.

Muggleton, D. (2000). Inside subculture: The postmodern meaning of style. Oxford, UK: Berg.

Muggleton, D., \& Weinzierl, R. (2004). The post-subcultures reader. New York: Berg.

Murray, C. (1984). Losing ground: American social policy, 1950-1980. New York: Basic Books.

Park, R. (1925). Suggestions for the investigation of human behavior. In R. E. Park, E. W. Burgess, \& R. D. McKenzie (Eds.), The city. Chicago: University of Chicago Press.

Pike, E. (2005). Doctors just say "rest and take ibuprofen": A critical examination of the role of nonorthodox health care in women's sport. International Review for the Sociology of Sport, 40, 201-219.

Putnam, R. (2000). Bowling alone: The collapse and revival of American community. New York: Simon \& Schuster.

Redhead, S. (1993). Rave off: Politics and deviance in contemporary youth culture. Aldershot: Avebury.

Sabo, D. (1986). Pigskin, patriarchy and pain. Changing Men: Issues in Gender, Sex, and Politics, 16, 24-25.

Sammons, J. (1988). Beyond the ring: The role of boxing in American society. Urbana: University of Illinois Press.

Sanchez-Jankowski, M. (2002). Representation, responsibility and reliability in participant observation. In T. May (Ed.), Qualitative research in action (pp. 144-160). London: Sage.

Sánchez-Jankowski, M. (2008). Cracks in the pavement: Social change and resilience in poor neighborhoods. Berkeley: University of California Press.

Sandomir, R. (2007). From the edge of madness to the mainstream. New York Times. May 25. Sports. http:// www.nytimes.com/2007/05/25/sports/othersports/25ufc.html. Accessed January 22, 2010.

Searle, J. (1995). The construction of social reality. New York: Free.

Sewell, W. (1992). A theory of structure: Duality, agency, and transformation. The American Journal of Sociology, 98, 1-29.

Sheridan, S. (2007). A fighter's heart: One man's journey through the world of fighting. New York: Atlantic Monthly.

Silverman, A. (1998). John McCain breaks up a fight. Phoenix News Times. February 12. 1998. http://www. phoenixnewtimes.com/1998-02-12/news/john-mccain-breaks-up-a-fight/. Accessed January 22, 2010.

Smelser, N. (1999). The social edges of psychoanalysis. Berkeley: University of California Press.

Smith, T. (2008a). Passion work: The joint production of emotional labor in professional wrestling. Social Psychology Quarterly, 71, 157-176. 
Smith, T. (2008b). Pain in the act: The meanings of pain among professional wrestlers. Qualitative Sociology, $31,129-148$.

Stratton, D. (1985). Youth subcultures and their cultural contexts. Australian and New Zealand Journal of Sociology, 21, 194-218.

Sweetman, P. (2001). Stop making sense? The problem of the body in youth/sub/counter-culture. In S. Cunningham-Burley \& K. Backett-Milburn (Eds.), Exploring the body (pp. 183-200). Basingstoke: Palgrave.

Swidler, A. (1986). Culture in action: Symbols and strategies. American Sociological Review, 51, $273-286$.

Swidler, A. (2000). Talk of love: How culture matters. London and Chicago: University of Chicago Press.

Sykes, G., \& Matza, D. (1957). Techniques of neutralization: A theory of delinquency. American Sociological Review, 22, 664-670.

Taylor, C. (1985). Interpretation and the sciences of man. Philosophy and the human sciences: Philosophical papers 2. Cambridge: Cambridge University Press.

Thorne, B. (1993). Gender play: Girls and boys in school. New Brunswick: Rutgers University Press.

Thornton, S. (1996). Club cultures: Music, media and subcultural capital. Middletown: Wesleyan University Press.

Thornton, S. (1997). General introduction. In S. Thornton \& K. Gelder (Eds.), The subcultures reader. London and New York: Routledge.

Thrasher, F. M. (1927). The gang: A study of 1, 313 gangs in Chicago. Chicago: University of Chicago Press.

UFC (2009). The UFC fact sheet, Learn the UFC. http://www.ufc.com/index.cfm?fa=LearnUFC.FactSheet. (Visited February 1, 2009).

Vaisey, S. (2009). Motivation and justification: Towards a dual-process theory of culture in action. The American Journal of Sociology, 114, 1675-1715.

van Bottenburg, M., \& Heilbron, J. (2006). De-sportization of fighting contests: The origins and dynamics of no holds barred events and the theory of sportization. International Review for the Sociology of Sport, 41, 259-282.

van Bottenburg, M., \& Heilbron, J. (2009). Dans la cage: Genèse et dynamique des combats ultimes. Actes de la Recherche en Sciences Sociales, 179, 32-45.

Wacquant, L. (1995a). Pugs at work: Bodily capital and bodily labour among professional boxers. Body and Society, 1, 65-93.

Wacquant, L. (1995b). The pugilistic point of view: How boxers think and feel about their trade. Theory and Society, 24, 489-535.

Wacquant, L. (2004). Body \& soul: Notebooks of an apprentice boxer. Oxford and New York: Oxford University Press.

Wacquant, L. (2009). Habitus as topic and tool: Reflections on becoming a prizefighter. In W. Shaffir, A. Puddephatt, \& S. Kleinknecht (Eds.), Ethnographies revisited (pp. 137-151). New York: Routledge.

Weber, M. (1946). Class, status, party. In H. H. Gerth \& C. W. Mills (Eds.), From Max Weber: Essays in sociology (pp. 180-195). New York: Oxford University Press.

Weber, M. (1978 [1925]). Economy and society, vol. I. Berkeley: University of California Press.

Weinreb, M. (2007). A sport on the edge takes aim at the mainstream. New York Times. February 6. Sports. http://www.nytimes.com/2007/02/06/sports/othersports/06fight.html?scp=22\&sq="Michael +Weinreb"\&st=nyt.

Wheaton, B. (2004). Understanding lifestyle sport: Consumption, identity and difference. London: Routledge.

Wheaton, B. (2007). After sport culture: Rethinking sport and post-subcultural theory. Journal of Sport and Social Issues, 31, 283-307.

Widdicombe, S., \& Wooffitt, R. (1995). The language of youth subcultures: Social identity in action. Hemel Hempstead: Harvester Wheatsheaf.

Willis, P. (1976). Learning to labor. Lexington: D.C. Health.

Woodward, K. (2008). Hanging out and hanging about: Insider/outsider research in the sport of boxing. Ethnography, 9, 536-560.

Young, K., \& Atkinson, M. (2008). Introduction: A subcultural history. In K. Young \& M. Atkinson (Eds.), Tribal play: Subcultural journeys through sport, research in the sociology of sport (Vol. 4, pp. 1-46). Bingley: Emerald Group Publishing Limited.

Young, K., White, P., \& McTeer, W. (1994). Body talk: Male athletes reflect on sport, injury, and pain. Sociology of Sport Journal, 11, 175-194.

Zorbaugh, W. (1929). The Gold Coast and the slum. Chicago: University of Chicago Press. 
Corey M. Abramson is a PhD candidate in the Department of Sociology and the manager of the Center for Urban Ethnography (http://cue.berkeley.edu/) at the University of California, Berkeley. His research focuses primarily on the relationship between culture, stratification, and bodily practice in everyday life across varying social contexts. His dissertation is a comparative ethnographic study of the ways members of different socio-economic and racial groups manage the physical and social demands brought about by the aging body.

Darren Modzelewski earned his PhD in Anthropology at the University of California Berkeley, in 2010. His current research focuses on the intersection of anthropological and legal constructs of identity, ethnicity, and culture. His dissertation explores how archaeologists link past and present Native peoples in contemporary legal and political contexts, and to what effect. 